\author{
UNIVERSIDADE DE BRASÍLIA \\ FACULDADE DE EDUCAÇÃO FÍSICA \\ PROGRAMA DE PÓS-GRADUAÇÃO STRICTO-SENSU EM \\ EDUCAÇÃO FÍSICA
}

\title{
EFEITOS DE DIFERENTES PROTOCOLOS DE TREINAMENTO RESISTIDO NA FUNÇÃO NEUROMUSCULAR EM ADOLESCENTES
}

Ari Rodrigo Assunção

Brasília, 2015 


\title{
EFEITOS DE DIFERENTES PROTOCOLOS DE TREINAMENTO RESISTIDO NA FUNÇÃO NEUROMUSCULAR EM ADOLESCENTES
}

\author{
ARI RODRIGO ASSUNÇÃO RODRIGUES
}

Dissertação apresentada à Faculdade
de Educação Física da Universidade de
Brasília, como requisito parcial para
obtenção do grau de Mestre em
Educação Física.

ORIENTADOR: PROF. DR. PAULO ROBERTO VIANA GENTIL 


\section{EFEITOS DE DIFERENTES PROTOCOLOS DE TREINAMENTO RESISTIDO NA FUNÇÃO NEUROMUSCULAR EM ADOLESCENTES}

Dissertação aprovada como requisito parcial para obtenção do título de Mestre em Educação Física pelo Programa de Pós-Graduação da Faculdade de Educação Física da Universidade de Brasília.

Banca examinadora:

Prof. Dr. Paulo Roberto Viana Gentil

(Orientador - FEF/UnB)

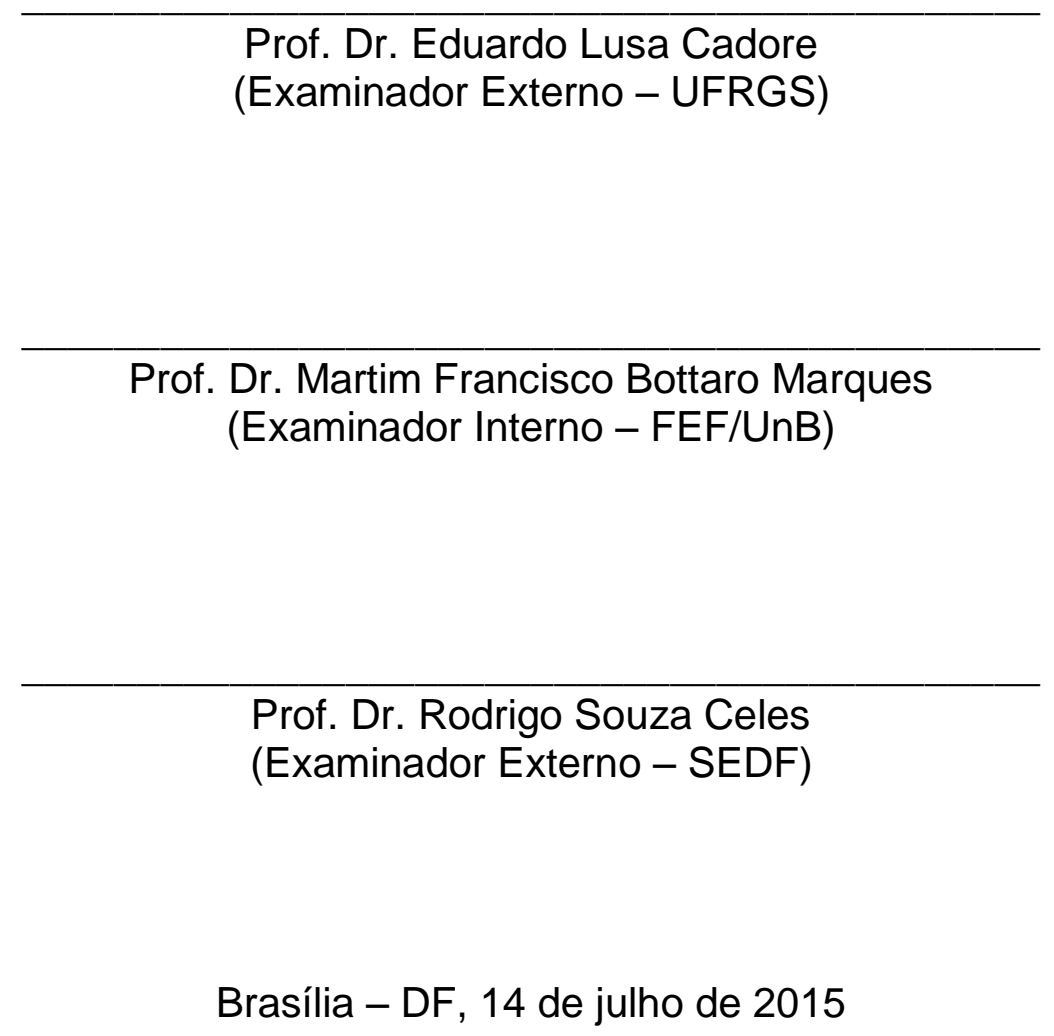




\section{DEDICATÓRIA}

Dedico esse trabalho aos meus filhos, Clara e Bernardo, por me encherem de vida e por serem meus melhores professores.

Obrigado pela paciência e amor. 


\section{AGRADECIMENTOS}

Agradeço ao meu orientador professor Dr. Paulo Gentil, pela dedicação na orientação do trabalho, por acreditar em meu potencial, pela enorme disposição em ajudar, auxiliando também em meu crescimento profissional, e pela amizade, nas horas difíceis e nas horas boas!

Ao professor PhD. Martim Bottaro pelos ensinamentos e apoio durante essa jornada.

Aos professores que me auxiliaram com enorme apoio e disposição na condução da pesquisa Marcelo Ferraz, Daiane Priscilla, Euler Alves, Patrícia Kapassi, Gilson e Paulinho. Vocês foram incríveis ao longo dessa caminhada! Vamos comemorar com um lanche na Vitamina Central!

Ao Cief pelo espaço cedido para execução da pesquisa.

Aos amigos do grupo de pesquisa do Laboratório de Treinamento de Força Ms. André Martorelli, Ms. Saulo Martorelli, Dr. Rodrigo Celes, Dra. Maria Cláudia Pereira, Ms. Saulo Soares, Ms. Amilton Vieira, Mateus Bezerra, Vitor Alonso, Ms. Rafael Pompeu e Igor Eduardo.

Agradeço aos voluntários, pela participação, comprometimento e dedicação. Obrigado ao coordenador escolar, Daniel, e à direção da escola por todo apoio.

À Coordenação do Programa de Pós-Graduação em Educação Física da FEF-UnB.

Às minhas irmãs, amigos, técnicos e amigos do esporte e todos aqueles que acreditaram, torceram e me ajudaram nessa caminhada.

À minha esposa, Juliane Verdade, por todo apoio e incentivo.

À minha mãe (in memorian) por tudo. 


\section{SUMÁRIO}

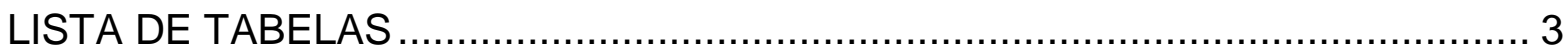

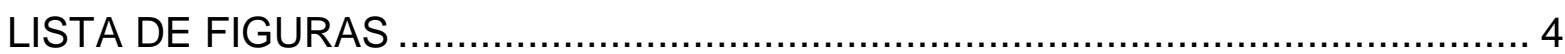

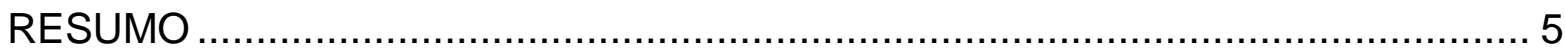

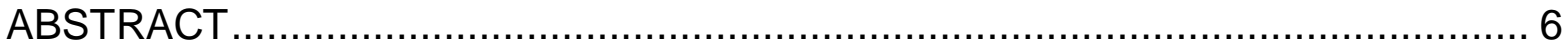

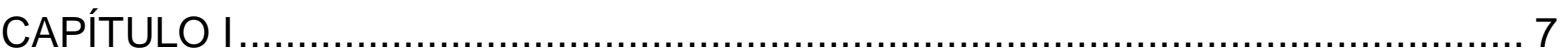

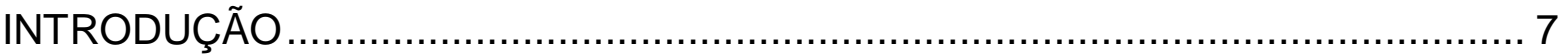

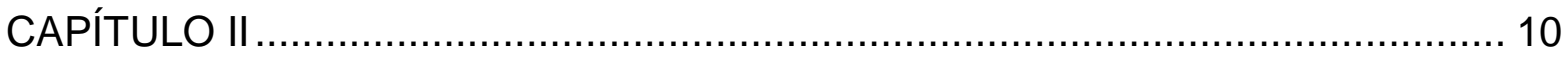

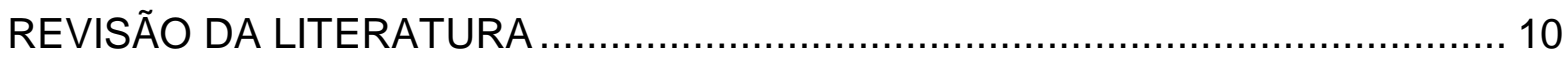

1 - Treinamento Resistido em adolescentes ........................................ 10

2 - Número de repetições - efeitos crônicos de diferentes protocolos ............... 15

3 - Comparações entre crianças, adultos e adolescentes .............................. 20

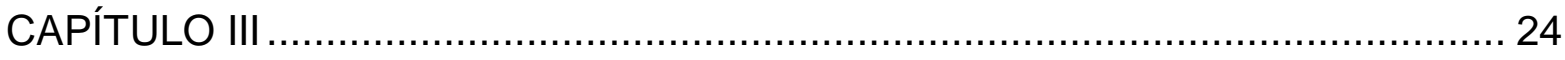

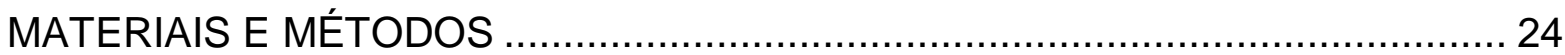

1 - Visão Geral do Estudo .................................................................... 24

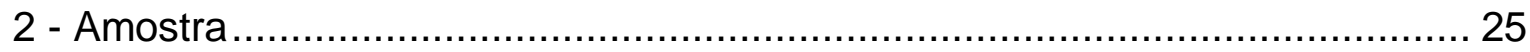

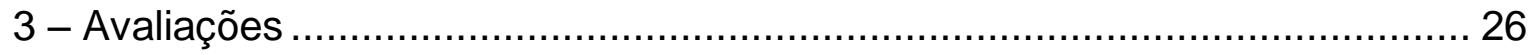

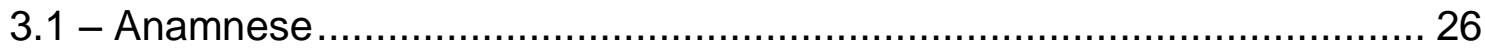

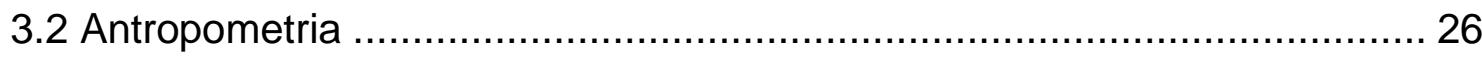

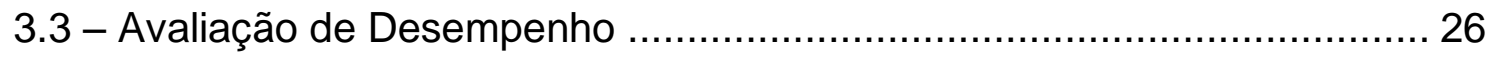

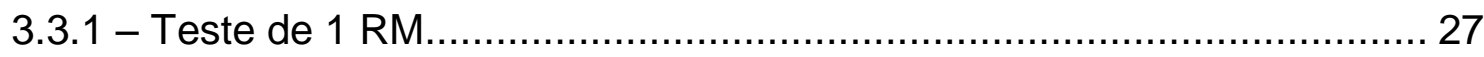

3.3.2 - Teste de Resistência de Força ............................................. 28

3.3.3 - Teste de Resistência de Força com Carga Inicial ............................. 29

4 - Treinamento Resistido....................................................................... 29

5 - Procedimentos Estatísticos ............................................................... 30

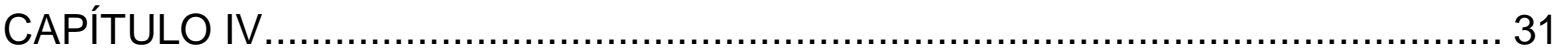


RESULTADOS

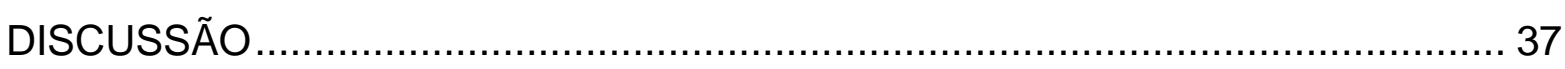

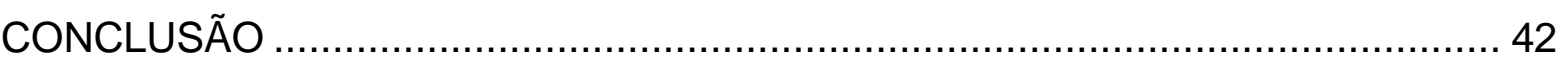

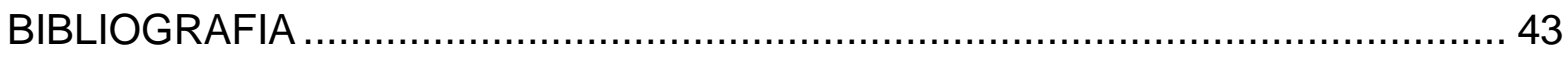

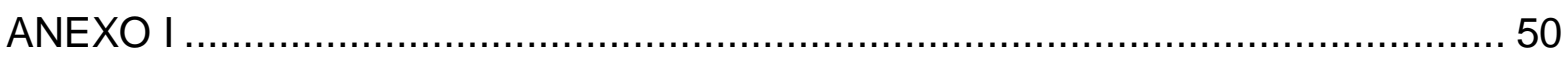

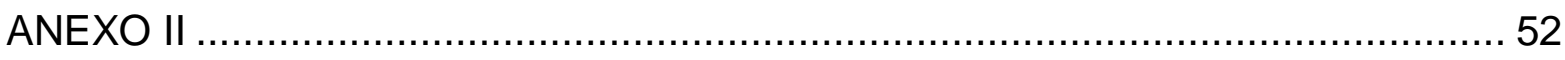

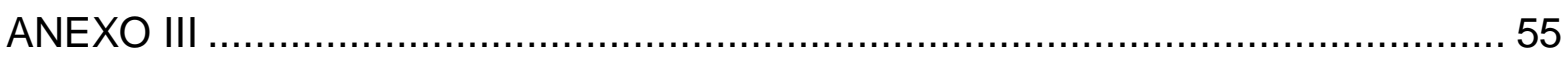

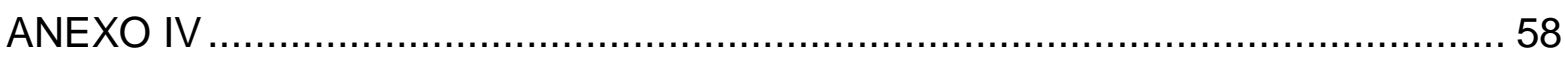




\section{LISTA DE TABELAS}

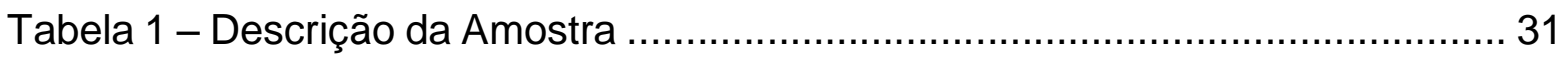

Tabela 2 - Tabela descritiva dos resultados dos testes pré e pós treinamento ....... 33 


\section{LISTA DE FIGURAS}

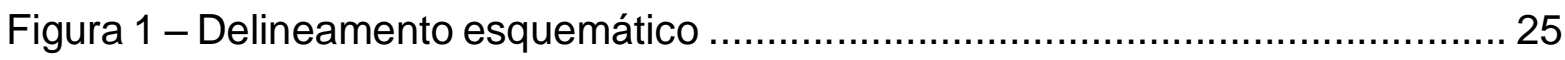

Figura 2 - Teste de 1 RM no agachamento no Smith Machine .............................. 28

Figura 3 - Teste de Resistência de Força no supino reto .................................... 28

Figura 4 - Valores de $1 \mathrm{RM}(\mathrm{Kg})$ pré e pós treinamento no supino para os grupos $\mathrm{AC}$,

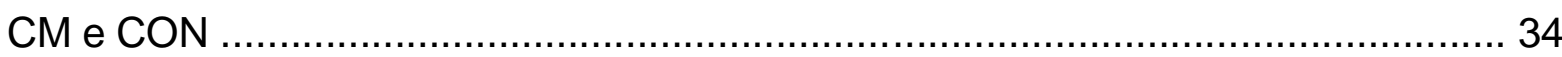

Figura 5 - Valores de $1 \mathrm{RM}(\mathrm{Kg})$ pré e pós treinamento no agachamento para os

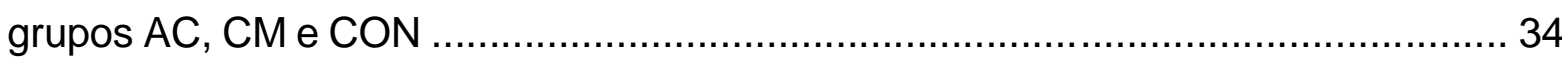

Figura 6 - Número de repetições com $70 \%$ de 1 RM pré e pós treinamento no supino

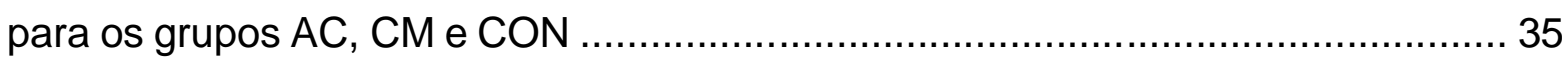

Figura 7 - Número de repetições com $70 \%$ do primeiro 1 RM pré e pós treinamento no supino para os grupos AC, CM e CON ....................................................... 35

Figura 8 - Número de repetições com $70 \%$ de 1 RM pré e pós treinamento no

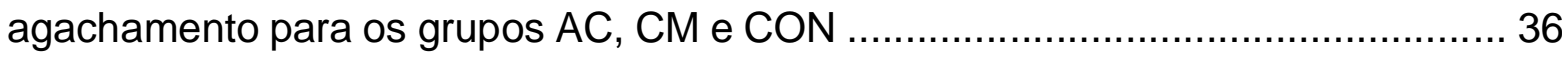

Figura 9 - Número de repetições com $70 \%$ do primeiro $1 \mathrm{RM}$ pré e pós treinamento no agachamento para os grupos $\mathrm{AC}, \mathrm{CM}$ e $\mathrm{CON}$ 36 


\section{RESUMO}

Objetivo: Comparar os efeitos de dois diferentes protocolos de treinamento resistido (TR) nos ganhos de força e resistência de força em adolescentes de ambos os sexos destreinados. Métodos: 45 adolescentes de ambos os sexos destreinados $(13,74$ anos \pm 0,76 anos; $161,32 \pm 7,53 \mathrm{~cm} ; 56,79 \pm 13,40 \mathrm{Kg})$ foram divididos aleatoriamente em 3 grupos: altas cargas e baixas repetições $(A C, n=17, M / F=$ 10/7), que executava entre 4 a 6 repetições máximas (RMs); cargas moderadas e altas repetições $(\mathrm{CM}, \mathrm{n}=16, \mathrm{M} / \mathrm{F}=7 / 9)$, que executava entre 12 a $15 \mathrm{RMs}$; e controle ( $C O N, n=12, M / F=2 / 10)$, que não realizou TR. O TR era executado durante 9 semanas, 2 vezes por semana. Foram realizados testes de $1 \mathrm{RM}$ e testes de resistência de força com $70 \%$ da $1 \mathrm{RM}$, no supino reto na barra e no agachamento no Hack Smith Machine. A análise estatística foi realizada por meio de testes de $\mathrm{t}$ para medidas dependentes e a comparação entre grupos foi realizada por meio de uma ANCOVA, usando os valores iniciais como covariantes. No teste de $1 \mathrm{RM}$ de supino, o grupo AC e CM aumentaram significativamente as cargas, passando de $31,41 \pm 7,08 \mathrm{Kg}$ para $36,05 \pm 9,07 \mathrm{Kg}$ e de $30,87 \pm 7,11 \mathrm{Kg}$ para $35,25 \pm 6,84 \mathrm{Kg}$, respectivamente. No teste de $1 \mathrm{RM}$ no agachamento, os grupos $\mathrm{AC}$ e CM significativamente aumentaram, respectivamente, de 61,17 $\pm 13,05 \mathrm{Kg}$ para 77,29 \pm $16.60 \mathrm{Kg}$ e $60,87 \pm 10,55 \mathrm{Kg}$ para 76,5 $\pm 14,35 \mathrm{Kg}$. No teste com $70 \%$ de $1 \mathrm{RM}$ houveram aumentos significativos no grupo $A C$, que foi de 11,35 \pm 4,47 para $13 \pm$ 4,27 RMs e no grupo CM, que foi de 10,93 $\pm 2,29$ para 13,31 $\pm 3,62 \mathrm{RMs}$, no supino. No agachamento, as RMs tiveram aumentos significativos, passando de 10,29 $\pm 3,98$ para $13,52 \pm 3,87$ no grupo $A C$ e de $11 \pm 5,87$ para $14,56 \pm 5,30$ no grupo CM.O grupo controle não mostrou ganhos significativos para nenhum dos testes realizados.

Conclusão: Os resultados apontam que para aumentar a força máxima e a resistência de força em adolescentes destreinados, pode-se utilizar protocolos com altas cargas e baixas repetições (AC) ou com cargas moderadas e altas repetições (CM). Os dados mostram não haver diferença entre os protocolos AC e CM para nenhuma das variáveis analisadas e ambos se mostraram eficientes para aumentar tanto a força máxima quanto a resistência de força.

Palavras-chave: treinamento resistido, adolescentes, repetições máximas. 


\begin{abstract}
Objective: To compare the effects of two different resistance training (TR) protocols in strength gains and strength endurance in adolescents of both sexes untrained. Methods: 45 adolescents of both sexes untrained (13.74 years \pm 0.76 years; 161.32 $\pm 7.53 \mathrm{~cm}, 56.79 \pm 13.40 \mathrm{~kg}$ ) were randomly assigned into 3 groups: high loads and low repetitions $(A C, n=17, M / F=10 / 7)$, which ran from 4 to $6 \mathrm{MRs}$; moderate loads and high repetitions $(\mathrm{CM}, \mathrm{n}=16, \mathrm{M} / \mathrm{F}=7 / 9)$, which ran from 12 to $15 \mathrm{MRs}$; and control ( $C O N, n=12, M / F=2 / 10)$, which had no TR. The TR was performed for 9 weeks, 2 times a week. $1 \mathrm{RM}$ tests were performed and strength endurance test with $70 \%$ of 1 RM in the bench press and squat in Hack Smith Machine. Statistical analysis was performed using t test for dependent measurements and comparison between groups was performed by means of an ANCOVA using baseline values as covariates. In test $1 \mathrm{RM}$ bench press, $\mathrm{AC}$ and $\mathrm{CM}$ group significantly increased loads, from $31.41 \pm 7.08$ $\mathrm{kg}$ to $36.05 \pm 9.07 \mathrm{~kg}$ and $30.87 \pm 7.11 \mathrm{~kg}$ for $35,25 \pm 6.84 \mathrm{~kg}$, respectively. $1 \mathrm{RM}$ squattest, the $\mathrm{AC}$ and $\mathrm{CM}$ groups significantly increased, respectively, $61.17 \pm 13.05$ $\mathrm{kg}$ to $77.29 \pm 16.60 \mathrm{~kg}$ and $60.87 \pm 10.55 \mathrm{~kg}$ to $76.5 \pm 14,35 \mathrm{~kg}$. In the test with $70 \%$ of $1 \mathrm{RM}$ there were significant increases in the $A C$ group which was $11.35 \pm 4.47$ to $4.27 \pm$ MRs 13 and CM group, which was $10.93 \pm 2.29$ to $13.31 \pm 3.62 \mathrm{RMs}$ in the bench press. In the squat, the RMs have significantly increased, from $10.29 \pm 3.98$ to $13.52 \pm 3.87$ in the $A C$ group and $11 \pm 5.87$ to $14.56 \pm 5.30$ in the CM group. The control group showed no significant gains for any of the tests. Conclusion: The results indicate that to increase the maximum strength and strength endurance in untrained teenagers can be used protocols with high loads and low repetitions (AC) or moderate loads and high reps (CM). The data show no difference between $A C$ and CM protocols for any of the variables analyzed and both were effective to increase both the maximum force and the strength of resistance.
\end{abstract}

Keywords: resistance training, teens, maximum repetitions. 


\section{CAPÍTULO I}

\section{INTRODUÇÃO}

O treinamento resistido (TR), também conhecido como treinamento de força ou treinamento com pesos ${ }^{1}$, tornou-se uma das formas mais conhecidas e praticadas de exercício, tanto para aprimorar o treinamento físico de atletas como para melhorar as aptidões físicas de adultos, idosos, crianças e adolescentes.

Nos últimos anos, as pesquisas que envolvem a prática de exercícios pela população infanto-juvenil tratam da forma e intensidade dos treinos e seus reais benefícios para a performance e a saúde, adicionando muitas informações ao assunto; entretanto, ainda não se tem explicações adequadas para inúmeros questionamentos relacionados aos efeitos da prática da atividade física aplicada a essa população 2,3 .

Estudos anteriores com crianças e adolescentes constantemente questionavam a segurança e eficiência de um treinamento de força ${ }^{4}$. Após as divulgações dos relatórios do NEISS (National Electronic Injury Surveillance System) nos Estados Unidos nos anos de 1979 e 1987, que descreveram dados de lesões em crianças e adolescentes relacionadas aos exercícios resistidos, essa atividade passou a ser considerada perigosa e com alto risco de lesão para estas idades ${ }^{4,5}$.

Entretanto, evidências posteriores indicam que o treino de força em crianças e adolescentes é mais seguro que a prática de esportes mais populares, como futebol e atletismo ${ }^{6}$, por exemplo. O Colégio Americano de Medicina do Esporte (ACSM), inclusive, destaca que não há nenhuma evidência científica atual de que o treinamento de força ou o levantamento de pesos são inerentemente perigosos ou que podem prejudicar o crescimento de crianças e adolescentes ${ }^{7}$. Quando devidamente supervisionada por profissionais capacitados, além de segura, a atividade com treinos resistidos pode gerar diversos benefícios, tais como: aumento da força e resistência muscular, melhora do desempenho esportivo, prevenção de lesões no esporte e em atividades recreativas, reabilitação de lesões, melhora da composição corporal, aumento da densidade mineral óssea, aumento da capacidade cardiorespiratória, diminuição de lipídios sanguíneos, melhoria do bem estar 
psicossocial, dentre outros ${ }^{1,5,8-14}$. Os benefícios do TR foram relacionados, também, à diminuição da mortalidade precoce ${ }^{15}$.

Os protocolos de treinamento de força usam diferentes combinações de volume e intensidade para definir seus métodos de treino, com mais repetições e menos carga ou menos cargas e mais repetições ${ }^{1}$. Desde os primeiros estudos sobre $T R$, as pesquisas apoiaram a ideia de especificidade da tarefa relacionada a combinações de séries/repetições específicas, confirmando a teoria de um continuum de resistência de força de DeLorme ${ }^{21}$ e Berger ${ }^{56}$.

Faigenbaum e colaboradores ${ }^{5,14}$ conduziram dois estudos em crianças. No primeiro ${ }^{5}$, os resultados mostraram que se obtém maiores ganhos de força máxima com maiores repetições e cargas moderadas (12 ou mais repetições). No segundo ${ }^{14}$, os resultados apontaram para ganhos similares em níveis de força máxima para os dois protocolos (menos que 6 repetições ou mais que 12 repetições), embora, por maiores ganhos de flexibilidade, o autor indique os treinos com mais repetições para essa população.

Em adultos, os estudos são contraditórios. Há estudos bem delineados que apontam que as adaptações induzidas pelo treinamento estão ligadas com as intensidades dos esquemas de treino. Assim, treinos com baixas repetições máximas (de 3 a 6 em média) e cargas mais altas seriam mais favoráveis ao ganho de força enquanto treinos com altas repetições (acima de 12) seriam mais eficazes para aumento de resistência muscular, embora não demonstrem diferença significativa para hipertrofia 2,16-24. Por outro lado, há outros estudos em que diferentes protocolos, tanto com baixas repetições máximas (RMs) e cargas elevadas quanto com cargas moderadas e altas RMs geram efeitos similares para aumento de força ${ }^{24-30}$.

Para os adolescentes, não foram encontradas pesquisas que tratam de diferentes protocolos de TR e seus efeitos para força e resistência de força. E como este grupo se encontra em uma fase de transição entre a infância e a idade adulta, e mostra dados intermediários, tanto em níveis hormonais quanto nas respostas agudas ao exercício ${ }^{31,32}$, não se sabe se os protocolos empregados se aproximariam dos aplicados em crianças ou em adultos. A relevância desse estudo baseia-se no melhor entendimento das respostas crônicas dos adolescentes ao TR, de modo a favorecer a prescrição de eficientes e seguros para essa população. 
Desse modo, o objetivo desse estudo foi comparar os efeitos de dois protocolos de TR, o de altas cargas (AC) e RMs entre 4 e 6 com o de cargas moderadas (CM) e RMs entre 12 e 15, no desenvolvimento de força máxima e resistência de força em adolescentes destreinados de ambos os sexos com idade entre 13 e 15 anos. 


\section{CAPÍTULO II}

\section{REVISÃO DA LITERATURA}

\section{1 - Treinamento Resistido em adolescentes}

Os avanços tecnológicos têm contribuído para a redução da produção dos níveis de força durante as atividades diárias da população em geral ${ }^{33}$. Esse fato tem sido apontado por diversas associações científicas, como o American College of Sports Medicine (ACSM) e a National Strength Conditioning Association (NSCA), que enfatizam a força muscular, como uma característica física básica, de vital importância para a manutenção da saúde, da capacidade funcional e melhoria da qualidade de vida.

O treinamento resistido (TR) é a forma mais difundida de treinamento de força e foi primeiramente inserido por DeLorme ${ }^{21}$, em militares que atuaram na Segunda Guerra Mundial com intuito de potencializar a força e hipertrofia muscular na reabilitação dos mesmos. Posteriormente, entre os anos de 1950 e 1960, foram realizados os primeiros estudos envolvendo controle e manipulação das diversas variáveis presentes do treinamento com pesos, como o número de séries e de repetições, frequência, intensidade, volume e período de descanso $0^{16,25,34-36}$.

Contudo, somente a partir da década de 80 a comunidade médica reconheceu a importância do treinamento com pesos ${ }^{37}$. Na década de 90 , o ACSM acrescentou o treinamento com pesos em suas diretrizes ${ }^{38} \mathrm{e}$, atualmente, o TR é destacado pelas principais organizações de saúde, como o próprio ACSM e o American Heart Association (AHA). A partir de então, os diferentes tipos de treinamentos de força vêm sendo um tópico de grande interesse da comunidade científica ${ }^{39}$. Atualmente, o treinamento de força tem demonstrado ser o método mais efetivo na melhoria da força musculoesquelética e, devido a isso, é atualmente recomendado e utilizado na manutenção da saúde e da aptidão física por essas e outras organizações ${ }^{40}$, sendo considerado um tipo de exercício altamente relevante ${ }^{40,41}$

A manipulação adequada dos fatores que envolvem o TR tende a eliminar os platôs naturais de treinamento, permitindo que níveis mais elevados de condicionamento muscular possam ser alcançados ${ }^{42}$. O TR também tem uma grande 
participação na melhoria de diversas variáveis de treinamento, como a força, a potência, a hipertrofia e a resistência muscular ${ }^{40}$.

Um crescente número de adolescentes está participando de programas de TR para melhorar sua saúde e qualidades físicas, tornando necessário saber se o treinamento com pesos seria indicado para essa população e qual protocolo seria o mais recomendado ${ }^{43,44}$.

Como em qualquer outro tipo de prática esportiva, existem alguns riscos que podem ser diminuídos consideravelmente se um conjunto de sugestões for seguido: planejamento e supervisão adequados, aquecimento específico e eficiente, objetivos reais e de acordo com as necessidades e habilidades do adolescente, maior atenção à técnica de execução e melhoria do controle de movimento e ambiente de treinamento livre de potenciais perigos ${ }^{7,10,45}$.

Por muitos anos o treinamento de força não era recomendado para crianças e adolescentes por causa do alto risco de lesão que era atribuído a essa atividade. Embora muitos fatores são responsáveis por essa crença, o medo generalizado quanto ao treinamento de força para crianças e jovens deveu-se, essencialmente, pelos dados divulgados pela Comissão de Segurança de Produto ao Consumidor dos Estados Unidos (EUA) através do Sistema Nacional de Vigilância Eletrônica de Lesões (NEISS). Esse sistema faz análise de todos os dados dos EUA quanto ao número total de lesões relacionadas a exercícios ou a equipamentos esportivos, utilizando dados de salas de emergência dos hospitais. Em 1979, o relatório do NEISS mostrava que mais da metade das lesões envolvendo levantamento de pesos envolvia pessoas entre 10 e 19 anos e o relatório de 1987 mostrava que 8590 pessoas com 14 anos ou menos foram levadas às emergências hospitalares por lesões durante a musculação4. Os dados do NEISS, no entanto, não faziam distinção entre lesões associadas com programas de TR devidamente planejados e supervisionados daqueles caracterizados por uma carga excessiva, orientação não qualificada, equipamento mal projetado, ou livre acesso ao equipamento ou à área ${ }^{10,45}$.

Em um estudo posterior, Hamil ${ }^{6}$ revelou que o índice de lesões em adolescentes durante atividades que envolvem o TR é menor que o de outros esportes populares, como o futebol, futebol americano, basquete ou atletismo. 0 número de lesões por $100 \mathrm{hs}$ de participação no treinamento com pesos foi de 0,0035; enquanto que no Rugby foi 1,92; no basquete foi de 1,03; e no futebol foi de 6,20. 
Uma preocupação tradicional em relação ao TR para crianças ou adolescentes é o potencial dano para a cartilagem de crescimento. A cartilagem de crescimento é um 'pré-osso', que é mais fraco do que o tecido conjuntivo adjacente e, supostamente, mais facilmente danificado por micro traumas repetidos. Contudo, até o momento, não há relatos de prejuízo para a cartilagem de crescimento em qualquer estudo que envolva TR. Além disso, não há nenhuma evidência para sugerir que o TR vá impactar negativamente no crescimento e na maturação durante a infância ou adolescência ${ }^{10}$.

Com relação às lesões, um estudo de Hejna ${ }^{46}$ verificou que o TR pode reduzir o índice de lesões e o tempo necessário para recuperação em atletas adolescentes. O estudo envolveu três grupos, o primeiro grupo fez treinos com peso nas fases pré competitiva e competitiva apenas; o segundo grupo, treinou com pesos durante o ano todo; o grupo controle não fez TR ou fez apenas 1 vez por semana ou menos, durante o período competitivo. Somados os dois primeiros grupos, o percentual de atletas lesionados foi de $26,2 \%$, enquanto o percentual de atletas lesionados no grupo controle foi de $72,4 \%$. Outro dado significativo mostra que o tempo de recuperação das lesões foi menor no grupo do TR, 2,02 dias, do que no grupo sem musculação, 4,82 dias.

A participação regular de jovens em programas de TR tem potencial de desenvolver habilidades motoras e melhorar a performance esportiva ${ }^{47}$. A esses benefícios somam-se outros, como: menor risco de morte prematura, melhor autoestima, menor ocorrência de depressão, melhora do perfil lipídico, potência muscular, massa corporal magra, densidade mineral óssea e força muscular ${ }^{1,5,8-}$ 13,15,48,49. Além disso, a participação em atividades destinadas a melhorar a aptidão física e saúde durante a infância e a adolescência, mostrou ser eficaz para manter a atividade física regular como uma escolha de estilo de vida permanente durante a idade adulta ${ }^{50}$.

Em um estudo com mais de um milhão e cem mil participantes acompanhados a partir de 16 a 19 e durante 24 anos, Ortega e colaboradores ${ }^{15}$ (2012), associaram a força muscular à diminuição de incidência de morte prematura. Os testes de força incluíam extensão de joelho, teste de preensão manual e flexão de cotovelo, além de medidas de pressão arterial (PA) e índice de massa corporal (IMC). Os resultados mostraram que ter uma alta força muscular na adolescência, avaliado por estes testes, está associado com um risco de $20-35 \%$ menor de mortalidade prematura 
devido a qualquer causa ou doença cardiovascular, independentemente do índice de massa corporal ou pressão arterial. Os dados mostram também, que os adolescentes mais fortes tiveram um risco de $20-30 \%$ menor de morte por suicídio e foram $15-65 \%$ menos propensos a ter qualquer diagnóstico psiquiátrico (tais como esquizofrenia e transtornos de humor), apoiando a noção de que as pessoas fisicamente mais fracas também podem ser mentalmente mais vulneráveis. Este estudo fornece fortes evidências de que um baixo nível de força muscular no final da adolescência está associado a todas as causas de mortalidade prematura a um nível semelhante como os dos fatores de risco clássicos, como índice de massa corporal ou a pressão arterial.

Em uma revisão sistemática de 2009, Ruiz e colaboradores investigaram se a aptidão física na infância e adolescência é um preditor de fatores de risco para doenças cardiovasculares, para qualidade de vida e para dor lombar na vida adulta. Os autores concluem que melhorias na força muscular durante a infância e adolescência são negativamente associadas com mudanças na adiposidade geral na vida adulta e que a composição corporal saudável na infância e adolescência está associada a um perfil cardiovascular saudável mais tarde na vida, e com um menor risco de morte ${ }^{51}$.

Em 2013, Dias ${ }^{48}$ conduziu um estudo com 44 adolescentes entre 13 e 17 anos para avaliar os efeitos do TR em adolescentes obesos. No grupo experimental, 24 voluntários treinavam musculação $3 \times$ sem durante 3 meses. Foram observadas redução na pressão arterial sistólica e diastólica, redução na frequência cardíaca de repouso, redução na circunferência da cintura e da relação cintura/quadril, redução no percentual de gordura total e redução da incidência de síndrome metabólica, além do aumento da força muscular. Com base nesses dados, os autores concluíram que - treinamento de força exclusivo resulta em benefícios metabólicos, cardiovasculares, na composição corporal e condicionamento físico de adolescentes obesos, reduzindo assim, fatores de risco para essa população.

Granacher et al. ${ }^{52}$ avaliaram os efeitos do treinamento balístico em 28 adolescentes com idade média de 16 anos. Durante 8 semanas, o grupo experimental se exercitou $2 \times$ sem, cumprindo o seguinte protocolo: 4 séries de 10 repetições com 30 a $40 \%$ de 1 RM no leg press, extensão e flexão de pernas, flexão plantar, adução, abdução e agachamento. O treinamento gerou diferença significativa para força máxima isométrica e salto contra movimento. Segundo os 
autores, o treinamento balístico de membros inferiores em adolescentes é uma modalidade de treinamento adequada para um ambiente escolar (particularmente durante as aulas de educação física) que produz melhorias nas variáveis de força.

Em um estudo realizado por Faigenbaum e colaboradores ${ }^{53}$ um grupo de meninos e meninas com idades entre 8 e 12 seguiram um programa de TR duas $x$ sem, durante 8 semanas. O grupo de treinamento realizou 5 exercícios: extensão de perna, flexão de perna, supino, desenvolvimento de ombros e rosca bíceps. Ambos os grupos mantiveram suas atividades de educação física na escola. Os testes foram: 6 repetições máximas na extensão da perna e no supino; salto vertical; e flexibilidade. O treinamento de força aumentou de forma significativa a força de 6-RM na extensão da perna (53,5\%) e no supino (41,1\%), enquanto os ganhos do grupo controle ficaram na média de 7,9\%. Também houve melhorias significativas na composição corporal: as dobras cutâneas diminuíram em 2,3\%, em média, no grupo experimental, em comparação com um aumento de 1,7\% no grupo controle.

O TR também se mostrou eficaz, para aumentar os níveis de atividade física espontânea em adolescentes. Em 2010, Eiholzer e colaboradores ${ }^{54}$ analisaram duas equipes juniores de hóquei no gelo com idade média de 13 anos. Um time, grupo experimental, praticou musculação 2 vezes por semana durante 4 meses e o outro time, grupo controle, não fez treinos resistidos. Os resultados mostram que o nível de atividade física espontânea aumentou em 25,5\% em 4 meses no grupo experimental e não aumentou no grupo controle. No período de 12 meses, o aumento foi de $13,5 \%$ para o grupo experimental enquanto no grupo controle houve um decréscimo de $9,5 \%$.

Assim, a participação regular de jovens em programas de TR tem potencial de desenvolver habilidades motoras e performance esportiva ${ }^{47}$. A esses benefícios somam-se outros, como: menor incidência de morte prematura, manutenção de atividades físicas na idade adulta, perfil cardiovascular mais saudável, melhora da autoestima, menor ocorrência de depressão, promoção de benefícios em relação ao perfil lipídico, potência muscular, massa corporal magra, densidade mineral óssea, controle do sobrepeso ou da obesidade e aumento da força muscular ${ }^{1,5,8-13,48,49}$. 


\section{2 - Número de repetições - efeitos crônicos de diferentes protocolos}

As variáveis dos programas de treinamento contribuem diferentemente para construir várias sessões singulares, descrevendo assim, diversos protocolos da sessão de treino. A partir do exame cuidadoso de cada uma das variáveis em detalhe e das tomadas de decisões sobre elas uma sessão de treinamento é elaborada, e como são muitas as alternativas de manipulação das variáveis, um número quase infinito de protocolos de sessão pode ser criado ${ }^{1}$. Todas as sessões de treinamento resultam em respostas fisiológicas específicas e eventualmente em adaptações, como resultado das escolhas feitas considerando cada uma das variáveis possíveis ${ }^{1,55}$.

A quantidade de resistência empregada em um exercício é um fator chave em programas de treinamento de força e é um importante estímulo relacionado às alterações observadas nas mensurações de força, potência e de resistência muscular ${ }^{1,55}$. Quando se elabora um programa de treinamento de força, a carga para cada exercício deve ser escolhida durante o planejamento e a utilização de repetições máximas é provavelmente o método mais acessível para determinar uma resistência específica de acordo com os objetivos do programa ${ }^{1}$.

O uso de repetições máximas (RMs) define a resistência específica que permite que apenas um número determinado de repetições seja realizado. Tipicamente, utiliza-se um número alvo de RM (por exemplo, 10 RMs) ou uma zonaalvo de RM (por exemplo, 3 a 5 RMs) de treinamento. Então, à medida que o praticante aumenta seu nível de força, a resistência é ajustada de modo que ele continue a empregar um verdadeiro número de RMs legítimos ${ }^{1}$.

Em adultos, há divergências. Alguns estudos apontam na direção de que um número menor de repetições (entre 3 e 6 RMs) com cargas mais altas são favoráveis ao ganho de força, mas não geram diferença significativa para hipertrofia, em relação aos métodos de altas repetições (acima de $10 \mathrm{RMs}$ ) com cargas menores, que, por sua vez, geram melhores resultados para resistência muscular. Outros autores, no entanto, refutam essa teoria e indicam em seus estudos que não há diferença entre altas ou baixas repetições para ganho de força, desde que as repetições sejam realizadas até a falha. 
Desde os primeiros estudos sobre TR, as pesquisas apoiaram a ideia de especificidade da tarefa relacionada a combinações de séries/repetições específicas, confirmando a teoria de um continuum de resistência de força de DeLorme ${ }^{21}$ e Berger $^{56}$ e indicaram, a partir daí, a relação de que cargas mais elevadas geram melhores resultados para força máxima. A obra clássica de DeLorme ${ }^{21}$ em 1945 sugeriu que um programa de treinamento de força utilizando baixas repetições e altas cargas geram adaptações favoráveis para força e potência, enquanto o treinamento com altas repetições e baixas cargas aumentam a resistência muscular, introduzindo o conceito de continuum de repetição no treinamento ("repetition training continuum").

Posteriormente, Berger realizou dois estudos que reforçaram essa sugestão. Um com 171 homens jovens que foram divididos em 9 diferentes grupos de TR. Durante 12 semanas, 3 x sem os grupos realizavam 1, 2 ou 3 séries de 2, 6 ou 10 repetições. Para ganhos de força os melhores resultados foram o do grupo de 3 séries e 6 repetições ${ }^{16}$. Em outro, se comparou o efeito de um conjunto de 2, 4, 6, 8, 10 e 12 RMs no supino, 3 x sem, sobre a força máxima e concluiu que a carga ideal para aumento da força máxima é entre 3 e $9 \mathrm{RMs}^{56}$.

Os resultados de Campos et al. ${ }^{20}$ apoiam as conclusões de DeLorme e Berger. Os autores realizaram um estudo onde 32 homens com 23 anos de média foram divididos em 4 grupos: baixas repetições com 4 séries de 3-5 RMs; repetições intermediárias com 3 séries de 9-11 RMs; altas repetições com 2 séries de 20-28 RMs; e o grupo controle que não treinou. Durante 8 semanas eles realizaram leg press, agachamento e cadeira extensora 2 x sem nas 4 primeiras semanas e $3 \times$ sem nas outras 4 semanas. Houve maiores ganhos de força máxima no grupo de baixas repetições em comparação com os outros grupos, e a resistência de força, medida pelo número máximo de repetições a $60 \% 1 \mathrm{RM}$, melhorou mais no grupo de altas repetições.

Anderson e Kearney ${ }^{22}$ também testaram a hipótese de DeLorme, investigando os efeitos de três programas de resistência muito diferentes sobre as adaptações de força. Quarenta e três homens em idade universitária foram aleatoriamente designados para um dos três grupos: altas cargas/baixas repetições (três séries de 6-8 RMs), resistência média/repetições médias (duas séries de 30-40 RMs), e baixas cargas/repetições elevadas (uma série de 100-150 RMs). Após 9 semanas de treinamento 3 dias por semana, o grupo de alta cargas/baixas repetições mostrou o maior ganho na força máxima (1 RM) e os piores resultados para resistência de força 
relativa (número máximo de repetições, utilizando 40\% de $1 \mathrm{RM}$ ) em comparação com os outros dois grupos, que tiveram ganhos mais expressivos nos testes de resistência de força.

Em um recente estudo, Schoenfeld et al. ${ }^{19}$ analisaram, em 17 homens treinados com idade média de 23 anos, o efeito de um treino chamado de powerlifting com 3 RMs e 7 séries e intervalos de 3 minutos entre as séries e outro chamado de bodybuilding com 3 séries de 10 RMs e intervalos de 1,5 minutos. O volume total de carga, ou seja, o número de repetições realizadas multiplicado pela carga, foi equalizado entre as duas rotinas e eram realizadas 3 sessões de treinos por semana. A hipertrofia foi analisada por ultrassonografia e a força máxima pelo teste de $1 \mathrm{RM}$ no supino na barra e no agachamento livre. Após 8 semanas, não foram observadas diferenças significativas na espessura muscular do bíceps braquial. Diferenças de força significativas foram encontradas em favor do grupo powerlifting para o supino, e uma tendência de maior aumento de força máxima no agachamento. Em conclusão, este estudo mostrou que tanto o treino bodybuilding quanto o powerlifting promovem aumentos semelhantes em tamanho muscular, mas o treino do tipo powerlifting é superior para aumentar a força máxima.

Mitchel e colaboradores ${ }^{18}$ chegaram a conclusões semelhantes. Durante 10 semanas, 3 vezes por semana, 18 homens com idade média de 21 anos, realizaram a extensão de joelhos em 3 protocolos diferentes: 1 série com $80 \%$ de 1 RM; 3 séries com $80 \%$ de $1 \mathrm{RM}$; e 3 séries a $30 \%$ de $1 \mathrm{RM}$, todos até a falha voluntária máxima. Apesar da carga de treinamento não impactar na magnitude da resposta hipertrófica, teve um claro impacto sobre os ganhos de força isotônica voluntária. Tanto os grupos que treinaram com $80 \%$ x 1 e $80 \%$ x 3 demonstraram um aumento maior na força de 1RM em comparação com o grupo $30 \% \times 3$. Estes resultados sugerem que o treino com uma carga relativa alta é necessário para maximizar os ganhos de força de 1RM no movimento treinado.

$\mathrm{Na}$ mesma direção aponta o estudo de Holm et $a l .{ }^{57}$. Os pesquisadores aplicaram um protocolo de exercícios resistidos em que o mesmo indivíduo treinava uma perna a 70\% de 1RM (carga alta, AC) e a outra perna a 15,5\% de 1RM (carga baixa, CM). Onze homens sedentários, com idade média de 25 anos, treinaram por 12 semanas em três sessões/semana. Foram realizadas análises por ressonância magnética, biópsia muscular, obtidos bilateralmente a partir de vasto lateral para determinação de miosina de cadeia pesada $(\mathrm{MHC})$, força máxima por meio de testes 
de $1 \mathrm{RM}$ e em um dinamômetro isocinético a $60 \% \mathrm{~s}$. Os resultados mostram que, apesar da força de 1RM aumentar significativamente em ambas as pernas (AC: $36 \pm$ $5 \%, C M: 19 \pm 2 \%)$, aumentou mais no grupo $A C(p<0,01)$. $E$, no isocinético, o grupo AC melhorou significativamente tanto na força concêntrica como na excêntrica, enquanto que no grupo $\mathrm{CM}$ permaneceu inalterada, indicando que cargas mais altas geram melhores resultados para ganhos de força.

Em uma meta-análise com o objetivo de identificar uma relação da doseresposta quantificável para 0 treinamento de força, Rhea e colaboradores ${ }^{58}$ analisaram 140 estudos com um total de 1.433 effect sizes (ES). Estudos realizados com uma intervenção de treinamento de força e contendo os dados necessários para calcular ES foram incluídos na análise. Os resultados demonstraram que há diferentes respostas dos protocolos utilizados com base no nível de condicionamento inicial dos participantes. Os treinamentos com uma intensidade média de 60\% de 1 RM ou aproximadamente 12 RMs provocam ganhos máximos em indivíduos não treinados, enquanto que treinar a $80 \%$ de $1 \mathrm{RM}$ ou cerca de $8 \mathrm{RMs}$ é mais eficaz para aqueles que são treinados. Os autores argumentam ainda, que os resultados também indicam quanto a necessidade de aumentar a carga de treinamento (progressão) para sobrecarregar suficientemente o sistema neuromuscular conforme a pessoa se torna mais acostumada ao TR.

Entretanto, há estudos que demonstram que os ganhos são similares para força tanto com cargas altas e baixas repetições quanto com cargas moderadas e altas repetições. Chestnut e Docherty ${ }^{26}$ estudaram os efeitos de 10 semanas de treino, 3 vezes por semana em 24 homens com idade média de 24 anos. Seis séries de 4 repetições até a falha para o primeiro grupo e 3 séries de 10 repetições máximas para o segundo grupo. Os grupos de 4RM e de 10RM obtiveram aumentos significativos e iguais em força, área transversal, tensão e circunferência. Estes resultados sugerem que protocolos com 4 RMs ou $10 \mathrm{RMs,}$, com o volume equiparado, produzem adaptações neuromusculares semelhantes. Resultados semelhantes foram encontrados por O'Shea ${ }^{25}$ ao testar em 30 homens durante 6 semanas de treinos os seguintes protocolos: 3 séries de 9-10; 5-6; ou 2-3 RMs. Nesse estudo também não foram encontradas diferenças para ganhos de força estática ou dinâmica.

Outro estudo que relatou não encontrar diferenças foi o de Withers ${ }^{27}$ que investigou o efeito dos seguintes protocolos de treinamento para aumento da força 
máxima: 3 séries $\times 7$ RMs, 4 séries $\times 5$ RMs e 5 séries $\times 3$ RMs em 55 voluntários distribuídos aleatoriamente para um dos três grupos. Todos os indivíduos realizaram dois treinos por semana durante 9 semanas na rosca bíceps, supino e agachamento. A força foi avaliada no início e final do experimento, por teste de $1 \mathrm{RM}$. Os melhores resultados em cada tentativa de rosca bíceps, supino, agachamento foram somados e divididos pelo peso corporal para dar uma razão entre resistência / peso. Os resultados indicaram que todos os grupos registraram ganhos de força altamente significativos. Uma análise de covariância mostrou que nenhum grupo alcançou melhores resultados, estatisticamente significativos, do que os outros grupos.

Em um estudo de Stone e Coulter ${ }^{24}$, cinquenta mulheres universitárias foram aleatoriamente designadas para um dos três grupos: altas cargas/baixas repetições, cargas médias/repetições médias e baixas cargas/repetições elevadas. Os três grupos treinaram os mesmos exercícios durante 9 semanas com 3 séries de 6-8 RMs, 2 séries de 15 a 20 RMs, e uma série de 30 a 40 RMs, respectivamente. $O$ teste de $1 \mathrm{RM}$ foi usado para testar a força máxima e os testes de resistência muscular consistiu em realizar o número máximo de repetições com uma carga e cadencias pré-estabelecidas. Houve um aumento da força para ambos os grupos, mas nenhuma diferença estatisticamente significativa entre eles para os testes de força máxima e resistência muscular.

Em crianças, dois estudos realizados por Faigenbaum ${ }^{5,14}$ apontaram na direção oposta ao que comumente se defende em adultos. No primeiro estudo, em 1999, onze meninas e 32 meninos com idades entre 5 e 12 anos realizaram 2 vezes por semana durante 8 semanas, 1 série com 8 RMs ou 1 série de 13 a 15 RMs. Os resultados demonstram que os dois protocolos geram ganhos de força em crianças, mas com vantagem significativa para o treino com altas repetições, tanto para a extensão de pernas quanto para o supino.

No segundo, em 2005, 23 meninas e 20 meninos com idades entre 8 e 12 anos realizaram uma série de 6 a $10 \mathrm{RM}$ ou uma série de 15 a $20 \mathrm{RM}$, duas vezes por semana ao longo de 8 semanas e as crianças do grupo controle não treinaram. O grupo de baixas repetições máximas $(A C)$ e o grupo de altas repetições máximas (CM) obtiveram significativamente maiores ganhos de força 1 RM (21\% e 23\%, respectivamente), em comparação com o grupo controle (1\%), mas sem diferenças entre si. Apenas o grupo CM obteve maiores ganhos no teste de resistência muscular de $15 \mathrm{RM}(42 \%)$ do que a registrada no grupo de controle (4\%). Entretanto, os 
próprios autores citam que o estudo foi muito longo e não se avaliou a maturação biológica, portanto, ao longo do tempo, os sujeitos podem ter saído da infância e entrado na adolescência. E, concluem que, para as crianças, os resultados favorecem a prescrição de uma escala de treinamento com altas repetições.

Em outros dois estudos anteriores ${ }^{53,59}$, Faigenbaum também percebeu que os resultados estavam de acordo com os encontrados na comparação de métodos acima citada. No primeiro estudo onde avaliava os efeitos do treinamento em duas vezes por semana mensurou um ganho de 74,3\% em média para força, e os voluntários do grupo experimental executavam entre 10 e 15 repetições. No segundo, o objetivo era avaliar os efeitos do treinamento e destreinamento. Porém, o treino era realizado com séries de 6 a 8 repetições, e os ganhos de força alcançaram entre $41,1 \%$ e $53,5 \%$ de aumento em relação aos valores de pré treino. O próprio autor conclui que, em treinos por períodos curtos, um conjunto de 6-8 repetições com uma alta carga pode ser abaixo do ideal para aumentar a força em crianças.

Assim, as pesquisas demonstram não haver um consenso nos melhores protocolos ou números de repetições mais adequados para aumento da força máxima e da resistência de força em adultos ou crianças, realçando a importância de mais estudos que tratem do tema.

\section{3 - Comparações entre crianças, adultos e adolescentes}

O período da adolescência, segundo a OMS (Organização Mundial da Saúde), acontece entre os 10 e 19 anos de idade, dividida em 2 períodos: a pré-adolescência (10 a 14 anos) e a adolescência (15 aos 19 anos, em média) ${ }^{60}$. Esse também é o critério adotado pelo Ministério da Saúde do Brasil e pelo Instituto Brasileiro de Geografia e Estatística - IBGE. Para o Estatuto da Criança e do Adolescente - ECA, o período vai dos 12 aos 18 anos $^{61}$. Para a National Strength and Conditioning Association (NSCA) o termo crianças refere-se a meninos e meninas que ainda não desenvolveram características sexuais secundárias (aproximadamente até a idade de 11 anos em meninas e 13 anos nos meninos; estágios de maturação sexual de Tanner 1 e 2). Este período de desenvolvimento é chamado de pré-adolescência. $O$ termo adolescência refere-se a um período entre a infância e a idade adulta e inclui 
meninas com idades entre 12-18 anos e meninos com idade entre 14-18 anos (estágios de maturação sexual de Tanner 3 e 4$)^{10}$.

Os adolescentes estão em fase de transição da infância para a idade adulta e seu organismo está passando por transições biológicas e fisiológicas dentro de um período acelerado de desenvolvimento mental, emocional, sexual, social e físico ${ }^{62}$. Em geral, a adolescência inicia-se com as mudanças corporais da puberdade e termina com a inserção social, profissional e econômica na sociedade adulta61.

Os efeitos do TR também são diferentes entre crianças, adolescentes e adultos, como demonstrado por Chen e colaboradores ${ }^{31}$. O estudo teve o objetivo de comparar o dano muscular dos músculos flexores do cotovelo e testar a hipótese de que a magnitude da lesão muscular aumenta com o avanço da idade. Os voluntários foram divididos em 3 diferentes grupos, cada um com 13 sujeitos destreinados: préadolescente 9-10 anos; adolescente 14-15 anos e pós adolescente 20-25 anos. Os grupos realizaram dois treinos com 30contrações excêntricas máximas. Vários marcadores de lesão muscular indireta foram medidos a partir do braço exercitado antes, imediatamente após, e 1-5 dias pós-exercício. Além disso, análises hormonais mostraram diferenças na concentração de testosterona com os valores menores para as crianças $(0,14 \mathrm{nmol} / \mathrm{L})$, intermediários para os adolescentes (9,37 nmol/L) e maiores para os adultos $(25,02 \mathrm{nmol} / \mathrm{L})$. O trabalho total realizado durante o exercício excêntrico foi de aproximadamente $28 \%$ para pré-adolescentes e de $70 \%$ para o grupo adolescente, quando comparado com o do grupo de adultos (100\%). O torque da contração voluntária máxima pré-excercício dos grupos pré-adolescentes e adolescentes também foi de aproximadamente 25 e $71 \%$, respectivamente, em relação ao grupo de adultos. $E$ as mudanças na contração voluntária máxima durante os protocolos utilizados foram menores para as crianças, intermediárias para os adolescentes e maiores para os adultos, assim, os resultados demonstram que a magnitude da lesão muscular foi maior nos adultos e menores para crianças, com valores intermediários para os adolescentes.

Em outro estudo que analisou as diferenças entre crianças, adolescentes e homens, Faigenbaum et al. ${ }^{32}$ sugerem que as recomendações para adultos podem não ser consistentes para as necessidades e habilidades das crianças e adolescentes. O objetivo do estudo foi avaliar o desempenho no supino em meninos (idade 11,3 \pm 0,8 anos), adolescentes (idade de 13,6 0,6 anos) e homens (idade de $21,4 \pm 2,1$ anos) a diferentes tempos de intervalos de recuperação (IR). Cada 
participante realizou três séries com uma carga de 10 repetições máximas com um 1, 2 e 3 minutos de IR entre as séries, em ordem aleatória e em dias não consecutivos. Os resultados indicaram que crianças e adolescentes são capazes de fazer mais repetições com a carga de 10 RM no supino, com qualquer um dos três intervalos de recuperação, do que os homens e que os adultos podem precisar de intervalos de recuperação de pelo menos 3 minutos entre as séries; os adolescentes podem exigir intervalos de, pelo menos, 2 minutos; e crianças podem precisar de apenas 1 min de intervalo para minimizar as reduções de carga e atingir o maior volume possível de repetições. Dando suporte, assim, a hipótese de que crianças e adolescentes se recuperam mais rapidamente do que os homens nos treinamentos resistidos de carga moderada, indicando que os treinos devem ser planejados de acordo com objetivos e idades dos sujeitos.

Outros estudos envolvendo crianças, adolescentes e adultos, reforçam as respostas específicas da idade intermediária entre a infância e a fase adulta. Bottaro e colaboradores ${ }^{63}$ compararam o efeito de diferentes intervalos de recuperação nas respostas metabólicas e neuromusculares de crianças e adolescentes entre as séries de exercícios resistidos. Os resultados indicaram que as crianças se recuperam mais rapidamente do que os adolescentes entre as séries do exercício de extensão dos joelhos a $60^{\circ} \cdot \mathrm{s}-1$. No entanto, parece que em velocidades de contração elevadas $\left(180^{\circ} \cdot \mathrm{s}-1\right)$ as diferenças entre as duas faixas etárias são diminuídas. Além disso, os adolescentes experimentaram aumentos maiores em concentrações sanguíneas de Lactato. Segundo os autores, as crianças têm uma melhor capacidade para recuperar o desempenho muscular quando comparados com adolescentes porque as crianças dependem menos da glicólise anaeróbia para produção de energia e, consequentemente, se recuperam num ritmo mais rápido e tem uma maior capacidade de produção de torque nas séries subsequentes.

Logo depois, um estudo muito similar analisou o efeito de diferentes intervalos de recuperação entre as séries do TR entre adolescentes e adultos sobre a resistência à fadiga, número de repetições, percepção de esforço e volume total de treinamento. Tibana et al. ${ }^{64}$ relataram em seus resultados que os adolescentes tem uma capacidade maior de recuperação entre as séries, que um intervalo maior de recuperação resulta em mais repetições executadas, que conseguem cumprir um volume total de treino maior e que resistem mais à fadiga e explicam, ainda que 
superficialmente, que esses resultados acontecem devido à diferença na maturação do sistema neuromuscular.

Analisando esses dois trabalhos, percebemos que as crianças se recuperam mais rapidamente que os adolescentes, que por sua vez se recuperam mais rapidamente que os adultos. Fica claro, novamente, perceber o período de transição da infância para a idade adulta na qual o adolescente se encontra.

Tendo em vista as diferenças entre crianças, adolescentes e adultos nas respostas frente ao TR, bem como suas particularidades para prescrição dos protocolos de treinamento, é necessário entender as respostas específicas dos adolescentes frente aos protocolos AC e CM, pois eles podem apresentar resultados próprios ao seu estado maturacional, diferenciando-os dos adultos e crianças. 


\section{CAPÍTULO III}

\section{MATERIAIS E MÉTODOS}

\section{1 - Visão Geral do Estudo}

O estudo teve o modelo quase experimental ${ }^{65}$ de verificar 0 efeito de 9 semanas de TR, 2 vezes por semana, em 45 adolescentes de ambos os sexos com idade entre 13 e 15 anos. A amostra foi dividida aleatoriamente em três partes: o grupo experimental com altas cargas e RMs entre 4 e 6 ( $A C, n=17)$, o grupo experimental com cargas moderadas e RMs entre 12 e $15(\mathrm{CM}, \mathrm{n}=16)$ e o grupo controle sem TR (CON, $n=12)$. Durante o período de treinamento, foram realizadas 2 séries de cada exercício com intervalos de 1 minuto para as séries e de 2 minutos para os exercícios.

Para se observar os efeitos do programa de treinamento, os voluntários dos três grupos foram submetidos a uma bateria de testes antes e após o período de treinamento, assim dividida: Anamnese, Pesagem e Altura; Avaliação da força através do Teste de $1 \mathrm{RM}$ no supino reto na barra e no agachamento no Smith machine; Avaliação da Resistência de Força através do teste de repetições máximas com $70 \%$ de $1 \mathrm{RM}$ no supino reto na barra e agachamento no Smith machine. Os testes eram aplicados a cada semana, mantendo-se o intervalo entre as avaliações igual, tanto no pré teste quanto no pós teste.

Um delineamento esquemático do estudo está apresentado na figura 1. 


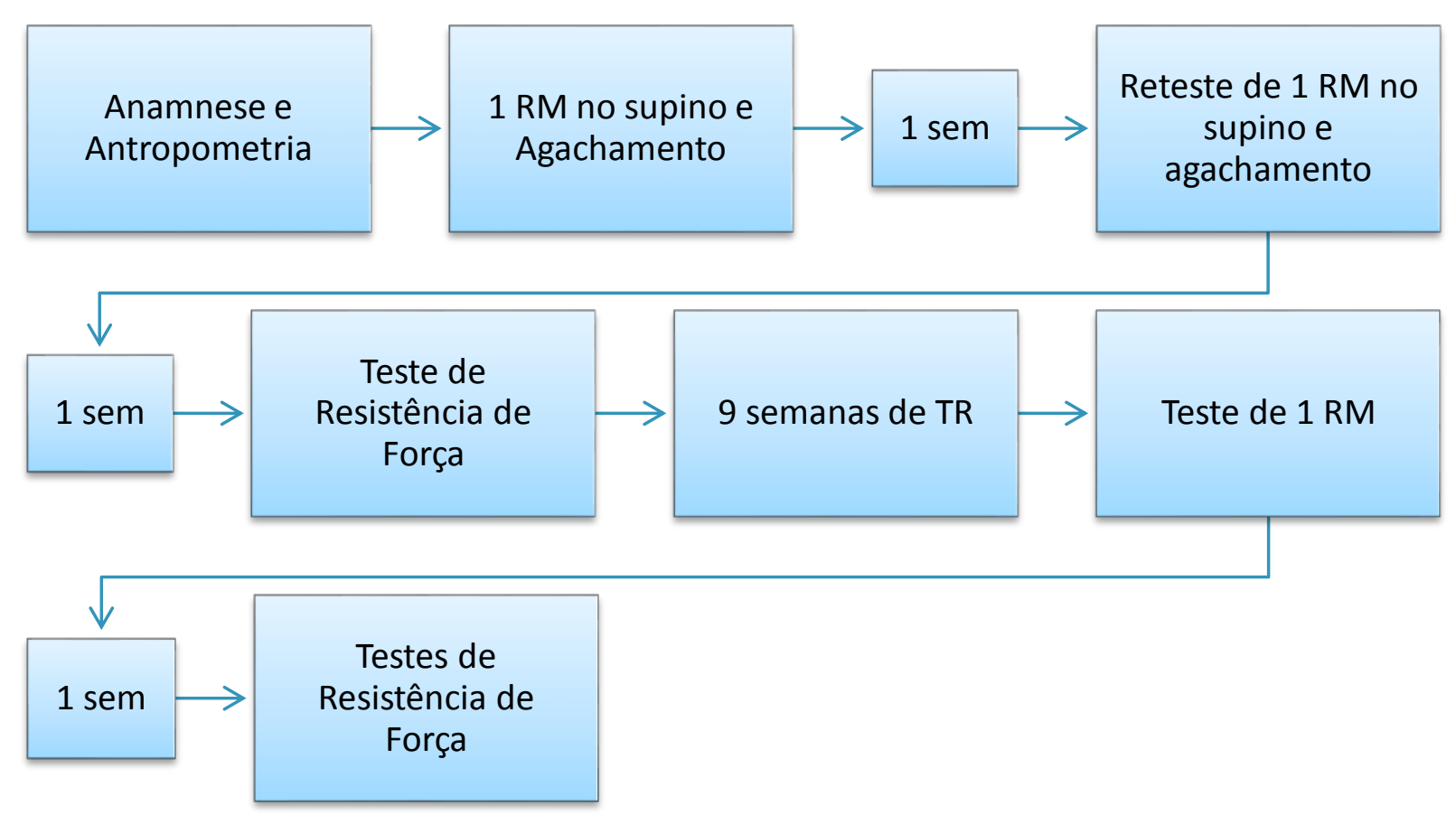

Figura 1: Delineamento esquemático

\section{2 - Amostra}

A pesquisa foi realizada com 45 estudantes meninos e meninas em idade de 13 a 15 anos.

Os critérios de inclusão foram não ter experiência em TR, aceitar o convite e obter a autorização dos pais para participar. Os critérios de exclusão foram presença de qualquer tipo de problema de saúde ou físico que impossibilite a realização ou pudesse ser agravado pelas atividades normais de treino, ausência em alguma etapa da coleta dos dados da pesquisa, assiduidade inferior a $80 \%$ dos treinos ${ }^{66}$, utilização de recursos ergogênicos ou mudanças relevantes nos hábitos nutricionais.

Os voluntários foram convidados a participar do estudo diretamente nas aulas de Educação Física da escola e a inclusão foi por voluntariado. A explanação da finalidade e objetivos deu-se na forma verbal e escrita (Termo de Consentimento Livre e Esclarecido) e com o aceite, apresentaram o Termo de Consentimento Livre e Esclarecido assinado pelo responsável no primeiro dia de testes e o Termo de Assentimento Livre e Esclarecido assinado pelo próprio aluno participante. 
O presente estudo foi submetido e aprovado pelo comitê de ética da Faculdade de Ciências da Saúde (FS) da Universidade de Brasília - UnB (Parecer № 997.140/2015, Anexo IV).

\section{3 - Avaliações}

\section{1 - Anamnese}

Foi realizada por um questionário composto de perguntas sobre os dados pessoais, hábitos diários, práticas de atividades físicas, tabagismo e consumo de bebidas alcoólicas e sobre o histórico médico pessoal e familiar relacionado a doenças coronarianas, cardiopatias, diabetes e doenças pulmonares, que forneceram segurança para o bom andamento da pesquisa.

\subsection{Antropometria}

As medidas usadas para caracterização da amostra foram a massa corporal e estatura. A massa corporal foi mensurada em uma balança digital EKS modelo 9800 com resolução de $50 \mathrm{~g}$ e a altura mensurada em centímetros em um estadiômetro Balmak modelo $111 \mathrm{com}$ resolução de $0,1 \mathrm{~cm}$.

\section{3 - Avaliação de Desempenho}

Os testes e retestes foram realizados na seguinte sequência antes do início do período de treino, com intervalo de 1 semana entre eles:

- Anamnese e antropometria.

- Pré teste 1: testes de $1 \mathrm{RM}$ no supino reto na barra e no agachamento no Smith machine.

- Pré teste 2: reteste de $1 \mathrm{RM}$ no supino reto na barra e no agachamento no Smith machine.

- Pré teste 3: teste de resistência de força no supino reto na barra e no agachamento no Smith machine. 
Após o treinamento:

- Pesagem.

- Pós teste 1: testes de 1 RM no supino reto na barra e no agachamento no Smith machine.

- Pós teste 2: testes de resistência de força com $70 \%$ de $1 \mathrm{RM}$ no supino reto na barra e no agachamento no Smith machine.

- Pós teste 3: testes de resistência de força com a carga do primeiro $70 \%$ de 1 $\mathrm{RM}$ do pré treino no supino reto na barra e no agachamento no Smith machine.

Todas as avaliações foram coordenadas pelo pesquisador e executados pelo mesmo e por mais 3 professores de Educação Física;

\subsection{1 - Teste de 1 RM}

O teste de $1 \mathrm{RM}$ foi realizado no supino reto na barra e agachamento no hack Smith, como pode ser visto na figura 1 . Ao longo de todos os procedimentos de teste houve acompanhamento de dois professores de Educação Física e foi oferecido o encorajamento verbal uniforme a todos os participantes da amostra.

A determinação da carga de 1RM seguiu o protocolo proposto por Kraemer e Fry ${ }^{67}:$ 1)aquecimento de oito repetições com a carga de 40 a 50\% da 1 RM estimada; 2) intervalo de um minuto seguido de seis repetições com 50 a $60 \%$ da $1 \mathrm{RM}$ estimada; 3) incremento do peso para determinação da 1RM em no máximo cinco tentativas com cinco minutos de intervalo entre cada tentativa; 4) o valor registrado foi o de uma repetição com o peso máximo levantado na última tentativa bem sucedida. 


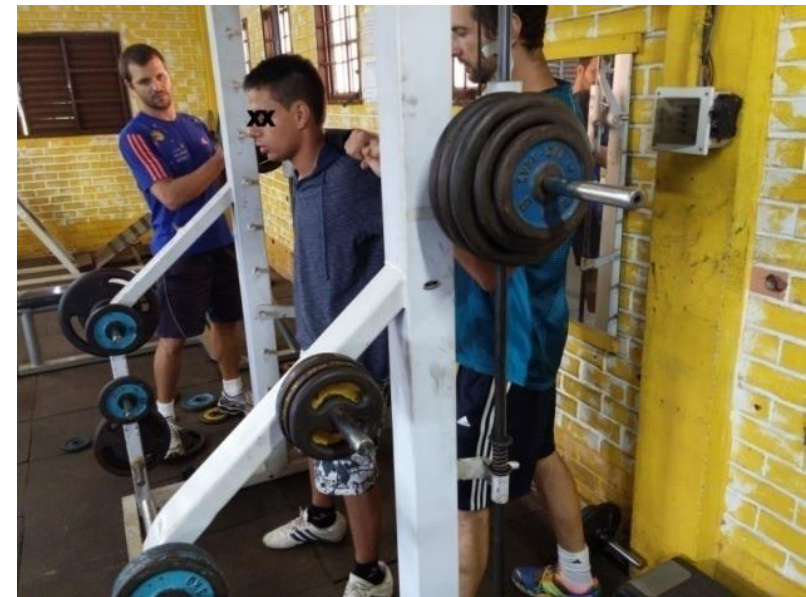

Figura 2 - Teste de 1 RM no agachamento no Smith Machine

\subsection{2 - Teste de Resistência de Força}

O teste de resistência de força, mostrado na figura 2, no supino reto na barra e no agachamento no hack Smith, foi precedido de uma série de aquecimento de 6 a 10 repetições com uma carga leve a moderada. Dois minutos após o aquecimento os indivíduos executaram o maior número de repetições possíveis com a carga de70\% de $1 \mathrm{RM}$ e velocidade controlada por um metrônomo (1,5s fase excêntrica e $1,5$ s fase concêntrica $)^{67,68}$. Os indivíduos foram verbalmente encorajados e foi registrado o número de repetições realizados até a fadiga voluntária.

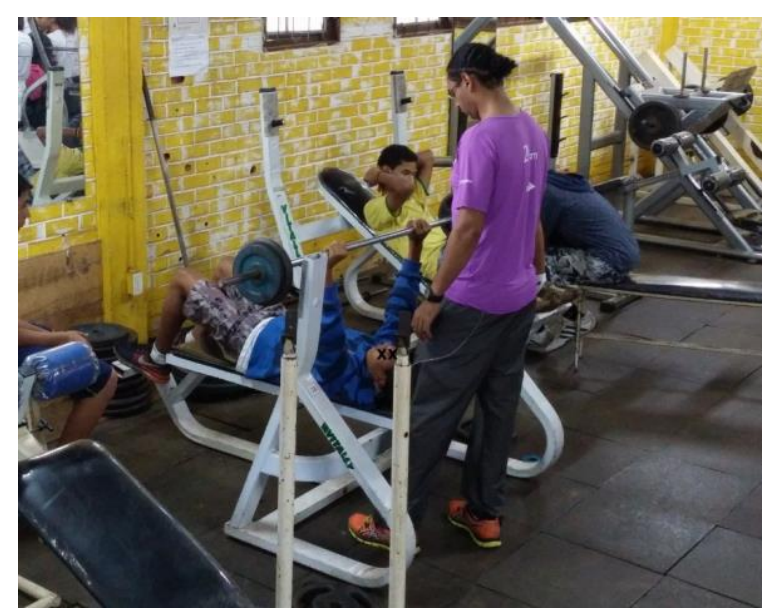

Figura 3 - Teste de Resistência de Força no supino reto na barra 


\subsection{3 - Teste de Resistência de Força com Carga Inicial}

O teste seguiu o mesmo protocolo do Teste de Resistência de Força, contudo, a carga utilizada nos testes pós estudo foi a mesma do primeiro teste de $1 \mathrm{RM}$, ou seja, de $70 \%$ do teste de 1 RM pré treino.

\section{4 - Treinamento Resistido}

Os grupos de exercício treinaram duas vezes por semana em dias não consecutivos, durante 9 semanas. Sessões de instrução foram dadas aos adolescentes sobre a oportunidade de compreender a importância da forma adequada de execução dos movimentos, bem como para que aprendam sobre os benefícios e riscos potenciais associados com o TR. Os adolescentes foram ensinados a gravar seus dados em fichas de registros de treinos e orientados a fazêlo durante todo o período de treinamento.

Os professores voluntários revisaram os registros de treino diariamente e fizeram os ajustes apropriados nas cargas de cada exercício, sempre que necessário. Cada sessão durou, em média, 40 minutos.

O programa de TR consistiu em um conjunto de 8 exercícios. Dois exercícios realizados com o uso do próprio peso corporal como resistência (flexão do tronco e flexão do quadril) e 6 exercícios com resistência externa: leg press $45^{\circ}$, cadeira extensora, supino reto na barra, crucifixo, puxada a frente pronada e remada na polia baixa. Nos exercícios com resistência externa, os indivíduos do grupo de baixas repetições e cargas altas $(A C)$ realizaram entre 4-6 RMs, enquanto os indivíduos do grupo de altas repetições e cargas moderadas (CM) realizaram de 12 a $15 \mathrm{RMs}$, conforme protocolos propostos pelo American College of Sports Medicine (ACSM) ${ }^{40}$.

Foram executadas 2 séries de cada exercício com intervalos de descanso de 1 minuto entre as séries e de 2 minutos entre os exercícios.

A última repetição de cada série deveria representar a falha concêntrica, definida como o ponto em que não se consegue realizar uma repetição completa. Durante as sessões de treinos as cargas de exercício foram selecionadas para provocar falha concêntrica dentro do intervalo de repetição prescrito. Quando necessário, a carga era ajusta da primeira para a segunda série, para que as repetições fossem mantidas dentro da margem desejada. Caso fosse possível 
realizar o limite superior das repetições prescritas em um exercício, a carga foi aumentada em $5 \%$ a $10 \%$ para a sessão seguinte.

Nos exercícios de peso corporal, os indivíduos de ambos os grupos realizaram 2 séries de 15 repetições para proporcionar um efeito geral condicionador. A ordem dos exercícios foi trocada a cada sessão para maximizar a ludicidade para os sujeitos, e nenhuma forma de TR fora do ambiente de pesquisa foi permitida. Todos os adolescentes tiveram autorização para participar das aulas de educação física da escola e para manter suas atividades recreativas durante todo o período do estudo.

O grupo controle recebeu a orientação de não participar de nenhum programa de TR. A influência dos programas de treinamento de resistência sobre índices de força muscular e resistência muscular localizada foram avaliados comparando as mudanças entre os grupos exercício e o grupo controle.

Os treinos foram realizados na sala de musculação do CIEF. Durante os treinos, os participantes receberam acompanhamento direto de professores de Educação Física com a proporção mínima de 1:3, um professor para cada 3 alunos. Houve constantes correções, observações técnicas e estímulos verbais para realização de esforços máximos.

\section{5 - Procedimentos Estatísticos}

Procedimentos estatísticos padrão foram usados para o cálculo da média e desvio padrão. As diferenças intragrupos foram avaliadas por meio de testes de $t$ para medidas dependentes. A comparação entre grupos foi realizada por meio de uma ANCOVA, usando os valores iniciais como covariantes. Caso fossem encontradas diferenças significativas, comparações múltiplas com correção do intervalo de confiança pelo método de Bonferroni foram usadas para comparações posteriores. O nível de significância foi estabelecido em $p \leq 0,05$. 


\section{CAPÍTULO IV}

\section{RESULTADOS}

A Tabela 1 apresenta as características descritivas dos 45 sujeitos participantes do presente estudo.

Tabela 1 - Descrição da amostra $(n=45)$.

\begin{tabular}{lccc}
\hline \multicolumn{1}{c}{ Variável } & $\mathrm{AC}$ & $\mathrm{CM}$ & $\mathrm{CON}$ \\
\hline $\mathrm{N}$ & 17 & 16 & 12 \\
Sexo (M / F) & $10 / 7$ & $7 / 9$ & $2 / 10$ \\
Idade (anos) & $13,82 \pm 0,95$ & $13,75 \pm 0,68$ & $13,66 \pm 0,65$ \\
Altura (cm) & $161,20 \pm 7,33$ & $162,18 \pm 5,15$ & $160,58 \pm 10,11$ \\
Massa corporal (Kg) & & & \\
Pré & $54,73 \pm 18,8$ & $58,55 \pm 10,17$ & $57,11 \pm 11,23$ \\
Pós & $54,66 \pm 17,7$ & $58,21 \pm 11,57$ & $57,26 \pm 9,61$ \\
\hline \multicolumn{2}{l}{ Legenda: AC (altas cargas), CM (carga moderada), CON (controle) }
\end{tabular}

$\mathrm{Na}$ tabela 2 temos os valores pré e pós treinamento para os grupos $\mathrm{AC}, \mathrm{CM}$ e CON, nos exercícios de supino reto na barra e agachamento no Smith Machine do teste de força máxima de $1 \mathrm{RM}$ e dos testes para resistência de força: $70 \%$ de $1 \mathrm{RM}$ e $70 \%$ do primeiro $1 \mathrm{RM}$.

Para os testes de $1 \mathrm{RM}$ avaliando a força máxima, os resultados pré e pós treino apontam, tanto no supino quanto no agachamento, uma diferença estatisticamente significativa $(p \leq 0,05)$ para os dois grupos que realizaram $o$ treinamento de força $\mathrm{AC}$ e $\mathrm{CM}$, mas sem diferença estatística entre eles. No teste de 1 RM de supino, o grupo AC aumentou a carga de 31,41 $\pm 7,08 \mathrm{Kg}$ para 36,05 $\pm 9,07$ $\mathrm{Kg}$ e o grupo CM passou de $30,87 \pm 7,11 \mathrm{Kg}$ para $35,25 \pm 6,84 \mathrm{Kg}$. No teste de $1 \mathrm{RM}$ no agachamento, os grupos AC e CM aumentaram, respectivamente, de 61,17 \pm $13,05 \mathrm{Kg}$ para $77,29 \pm 16.60 \mathrm{Kg}$ e 60,87 $\pm 10,55 \mathrm{Kg}$ para 76,5 $\pm 14,35 \mathrm{Kg}$. Não foram encontradas diferenças estatísticas para os resultados do grupo CON tanto no supino quanto no agachamento, como também pode ser visto na Tabela2.

Nos dois testes de resistência de força, com $70 \%$ de 1 RM pré e $70 \%$ de 1 RM pós treino e no teste pré e pós treinamento com $70 \%$ do primeiro $1 \mathrm{RM}$, 
novamente os grupos que participaram do treinamento de musculação $A C$ e CM demonstraram ganhos significativos pré e pós $(p \leq 0,05)$, mas sem diferenças estatísticas entre eles.

No teste que os sujeitos realizaram o máximo de repetições com $70 \%$ de $1 \mathrm{RM}$ o aumento do grupo AC foi de $11,35 \pm 4,47$ para $13 \pm 4,27$ RMs e do grupo CM foi de 10,93 $\pm 2,29$ para 13,31 $\pm 3,62 \mathrm{RMs}$, no supino. No agachamento, as repetições máximas passaram de $10,29 \pm 3,98$ para $13,52 \pm 3,87$ no grupo $A C$ e de $11 \pm 5,87$ para $14,56 \pm 5,30$ no grupo $C M$. No teste de resistência no qual os sujeitos executaram o máximo de repetições com a carga referente aos $70 \%$ do primeiro teste de $1 \mathrm{RM}$, o número de RMs no supino passou de 11,35 \pm 4,47 para 16,58 $\pm 5,42$ no grupo $A C$ e de 10,93 $\pm 2,29$ para 15,75 $\pm 3,73$ no grupo $C M$. Para o teste de agachamento, os resultados de RMs do grupo AC foram de 10,29 $\pm 3,98$ pré para $20,17 \pm 5,30$ pós treino e do grupo CM foram de $11 \pm 5,87$ pré para $24,75 \pm 10,85$ pós treinamento. $O$ grupo controle, não mostrou diferença significativa pré e pós para nenhum os testes de resistência de força. 
Tabela 2 - Tabela descritiva dos resultados dos testes pré e pós treinamento

\begin{tabular}{|c|c|c|c|}
\hline & $A C$ & CM & CON \\
\hline \multicolumn{4}{|l|}{$1 \mathrm{RM}$} \\
\hline \multicolumn{4}{|l|}{ Supino } \\
\hline Pré & $31,41 \pm 7,08$ & $30,87 \pm 7,11$ & $29,25 \pm 5,54$ \\
\hline Pós & $36,05 \pm 9,07^{\star \neq}$ & $35,25 \pm 6,84^{\star \neq}$ & $30,66 \pm 6,40$ \\
\hline Delta (\%) & 14,79 & 14,17 & 4,84 \\
\hline \multicolumn{4}{|c|}{ Agachamento } \\
\hline Pré & $61,17 \pm 13,05$ & $60,87 \pm 10,55$ & $62,66 \pm 10,66$ \\
\hline Pós & $77,29 \pm 16.60^{\star \neq}$ & $76,5 \pm 14,35^{\star \neq}$ & $66,25 \pm 11,39$ \\
\hline Delta (\%) & 26,35 & 25,67 & 5,72 \\
\hline \multicolumn{4}{|c|}{$\begin{array}{l}\text { Repetições com } 70 \% \text { de } 1 \text { RM } \\
\text { Supino }\end{array}$} \\
\hline Pré & $11,35 \pm 4,47$ & $10,93 \pm 2,29$ & $10,58 \pm 4,52$ \\
\hline Pós & $13 \pm 4,27^{\star \neq}$ & $13,31 \pm 3,62^{\star \neq}$ & $10,08 \pm 3,70$ \\
\hline Delta (\%) & 14,51 & 21,71 & $-4,72$ \\
\hline \multicolumn{4}{|c|}{ Agachamento } \\
\hline Pré & $10,29 \pm 3,98$ & $11 \pm 5,87$ & $8,081,24$ \\
\hline Pós & $13,52 \pm 3,87^{\star \neq}$ & $14,56 \pm 5,30^{\star \neq}$ & $9 \pm 1,20$ \\
\hline Delta (\%) & 31,43 & 32,39 & 11,34 \\
\hline \multicolumn{4}{|c|}{ Repetições com $70 \%$ do primeiro $1 \mathrm{RM}$} \\
\hline \multicolumn{4}{|l|}{ Supino } \\
\hline Pré & $11,35 \pm 4,47$ & $10,93 \pm 2,29$ & $10,58 \pm 4,52$ \\
\hline Pós & $16,58 \pm 5,42^{* \neq}$ & $15,75 \pm 3,73^{\star \neq}$ & $10,91 \pm 6,51$ \\
\hline Delta (\%) & 46,11 & 44,00 & 3,15 \\
\hline \multicolumn{4}{|c|}{ Agachamento } \\
\hline Pré & $10,29 \pm 3,98$ & $11 \pm 5,87$ & $8,081,24$ \\
\hline Pós & $20,17 \pm 5,30^{\star \neq}$ & $24,75 \pm 10,85^{\star \neq}$ & $10,16 \pm 1,89$ \\
\hline Delta (\%) & 96,00 & 125,00 & 25,77 \\
\hline
\end{tabular}

$\mathrm{Na}$ figura 4, vemos os resultados pré e pós treinamento para o teste de 1RM no supino e na figura 5 , os resultados do teste de $1 \mathrm{RM}$ no agachamento, pré e pós TR. 


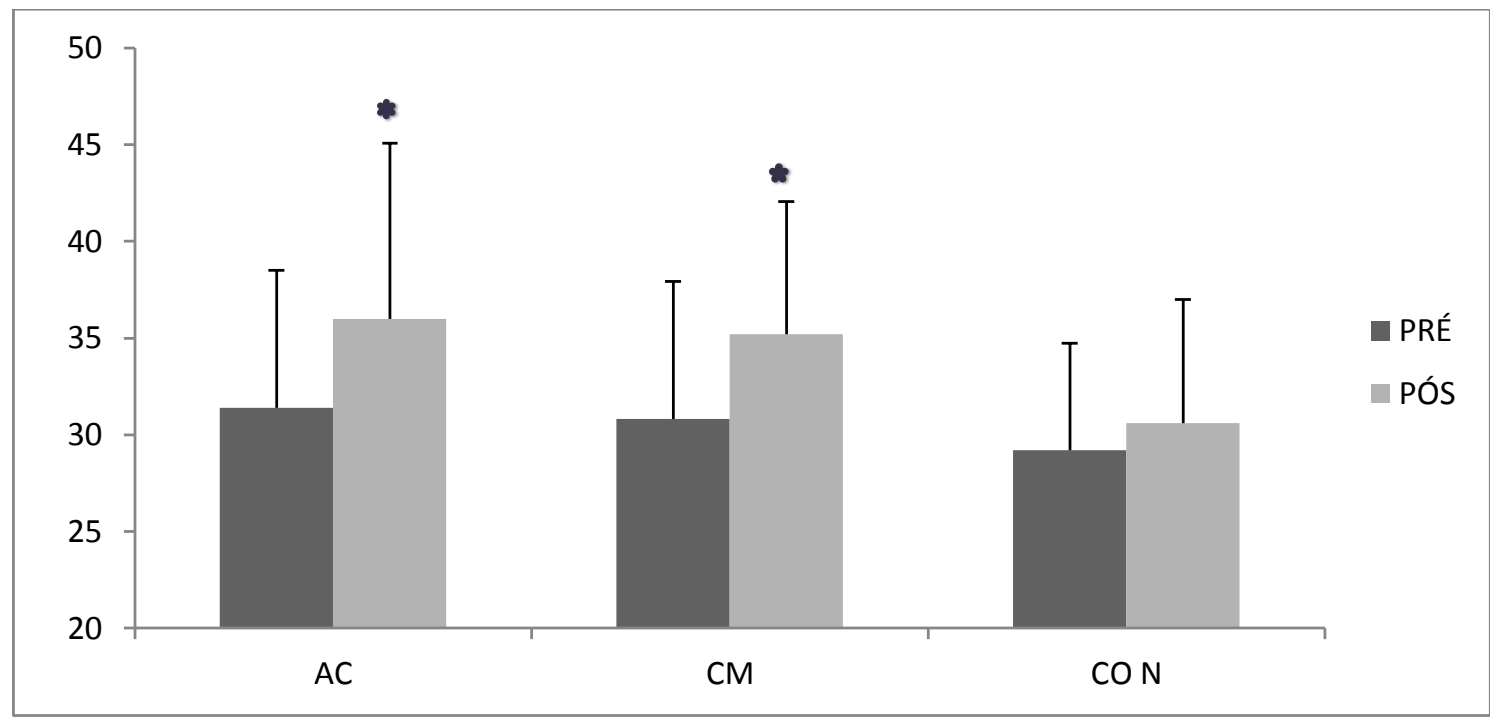

Figura 4 - Valores de $1 \mathrm{RM}(\mathrm{Kg})$ pré e pós treinamento no supino para os grupos $\mathrm{AC}, \mathrm{CM}$ e CON.

* diferença estatisticamente significativa pré e pós com $p \leq 0,05$

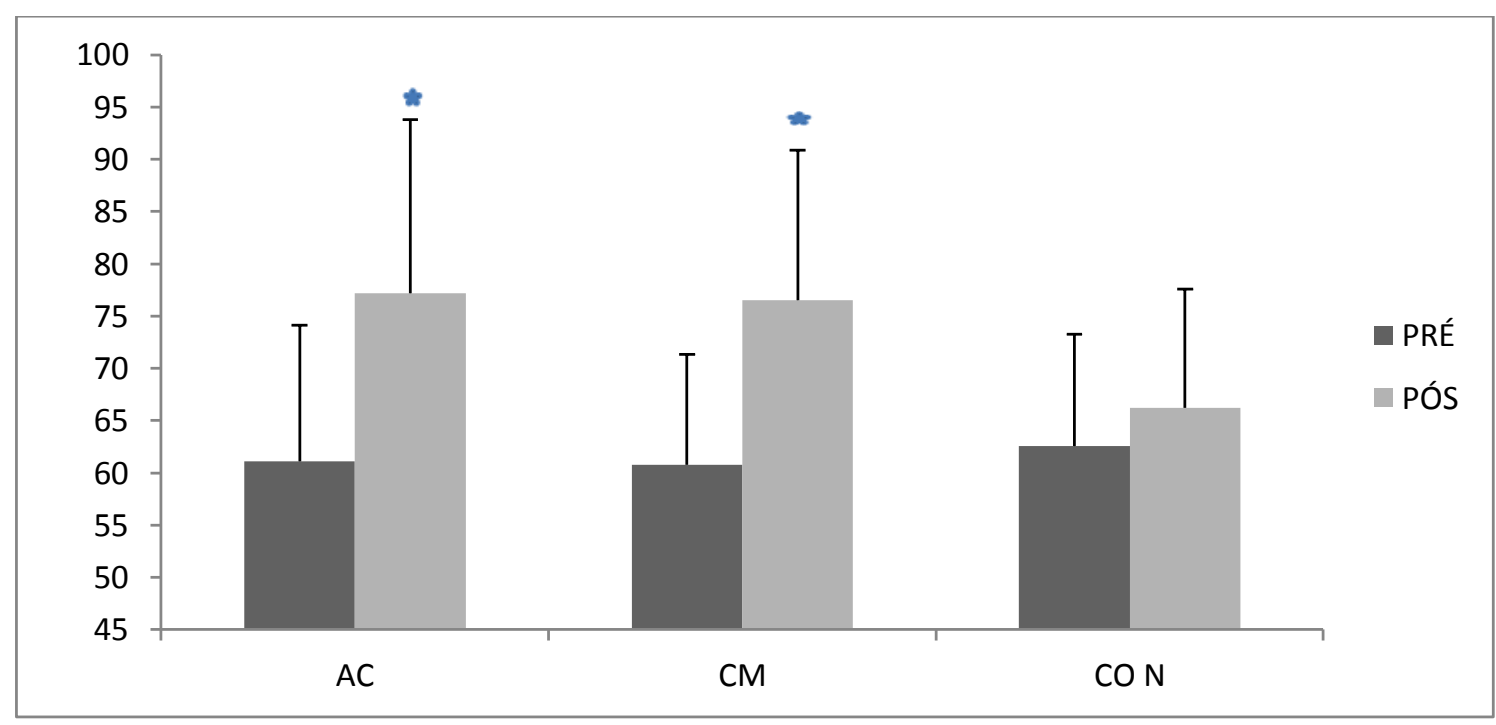

Figura 5 - Valores de $1 \mathrm{RM}(\mathrm{Kg})$ pré e pós treinamento no agachamento para os grupos AC, CM e CON.

* diferença estatisticamente significativa pré e pós com $p \leq 0,05$

As figuras 6 e 7 mostram os resultados dos testes de resistência de força no supino com $70 \%$ de $1 \mathrm{RM}$ pré e pós treinamento e com $70 \%$ do primeiro $1 \mathrm{RM}$, respectivamente. 


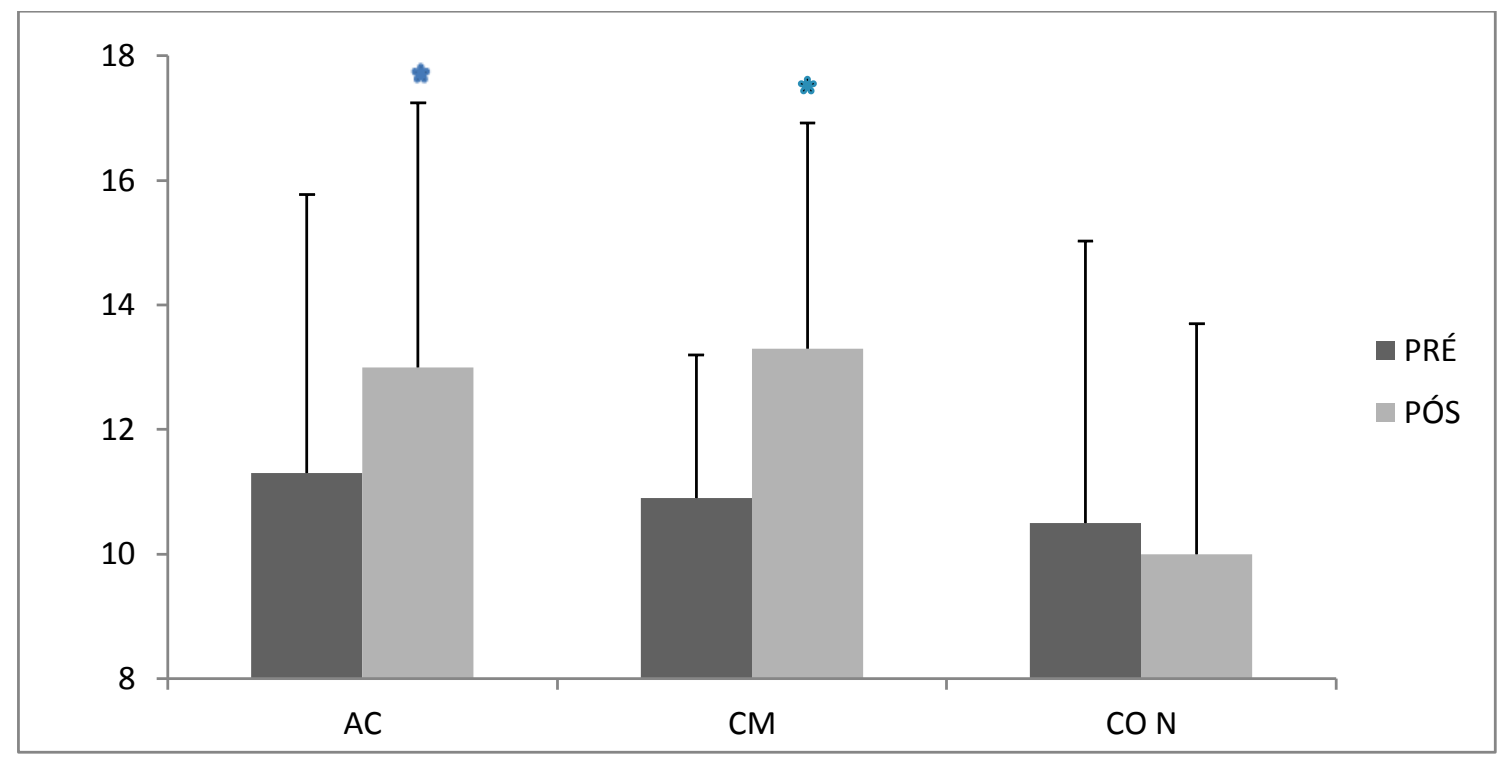

Figura 6 - Número de repetições com $70 \%$ de 1 RM pré e pós treinamento no supino para os grupos AC, CM e CON.

* diferença estatisticamente significativa pré e pós com $p \leq 0,05$

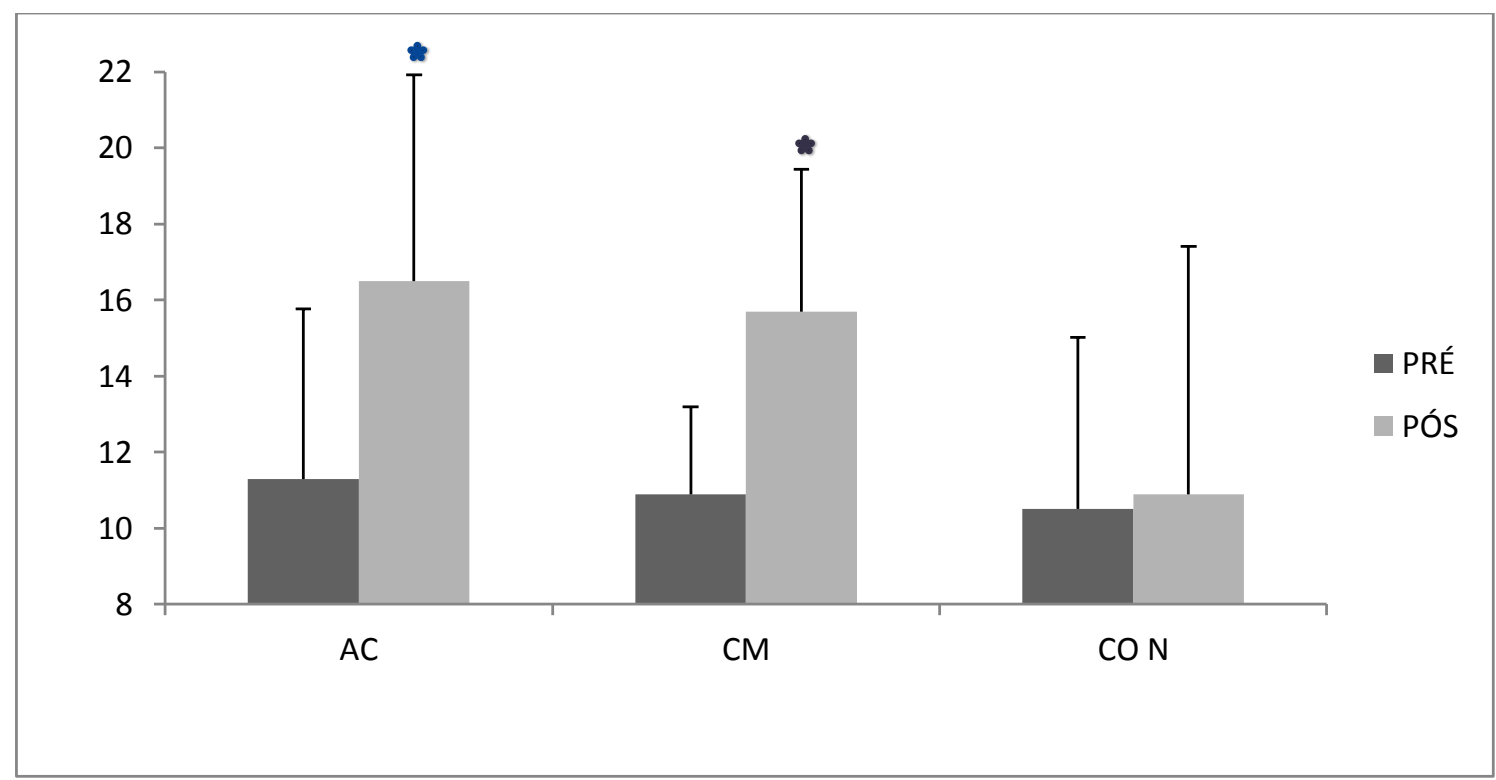

Figura 7 - Número de repetições com $70 \%$ do primeiro 1 RM pré e pós treinamento no supino para os grupos AC, CM e CON.

* diferença estatisticamente significativa pré e pós com $p \leq 0,05$

Para os resultados dos testes de resistência de força no agachamento com $70 \%$ de 1 RM pré e pós treinamento e com $70 \%$ do primeiro $1 \mathrm{RM}$ temos as figuras 8 e 9 abaixo. 


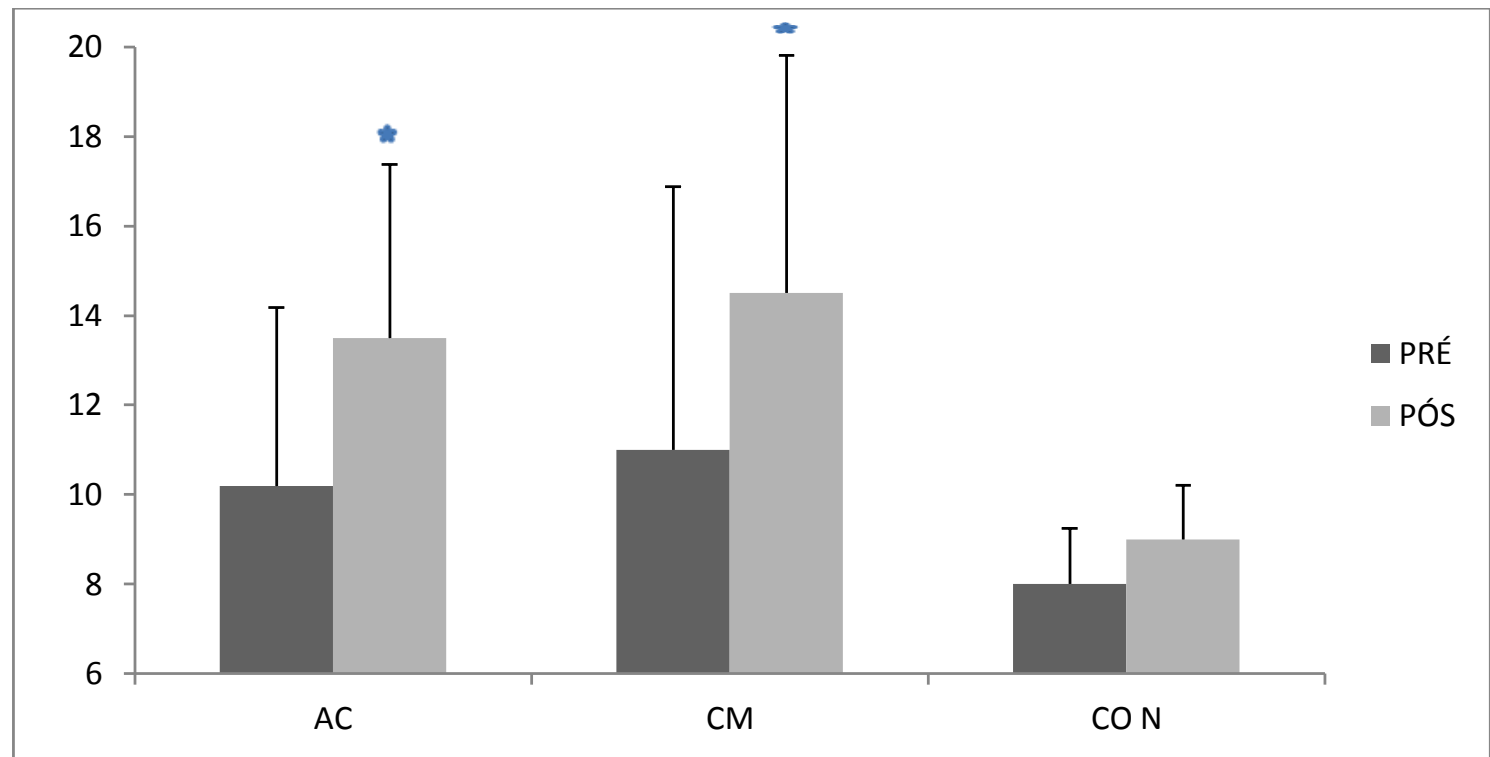

Figura 8 - Número de repetições com $70 \%$ de 1 RM pré e pós treinamento no agachamento para os grupos AC, CM e CON.

* diferença estatisticamente significativa pré e pós com $p \leq 0,05$

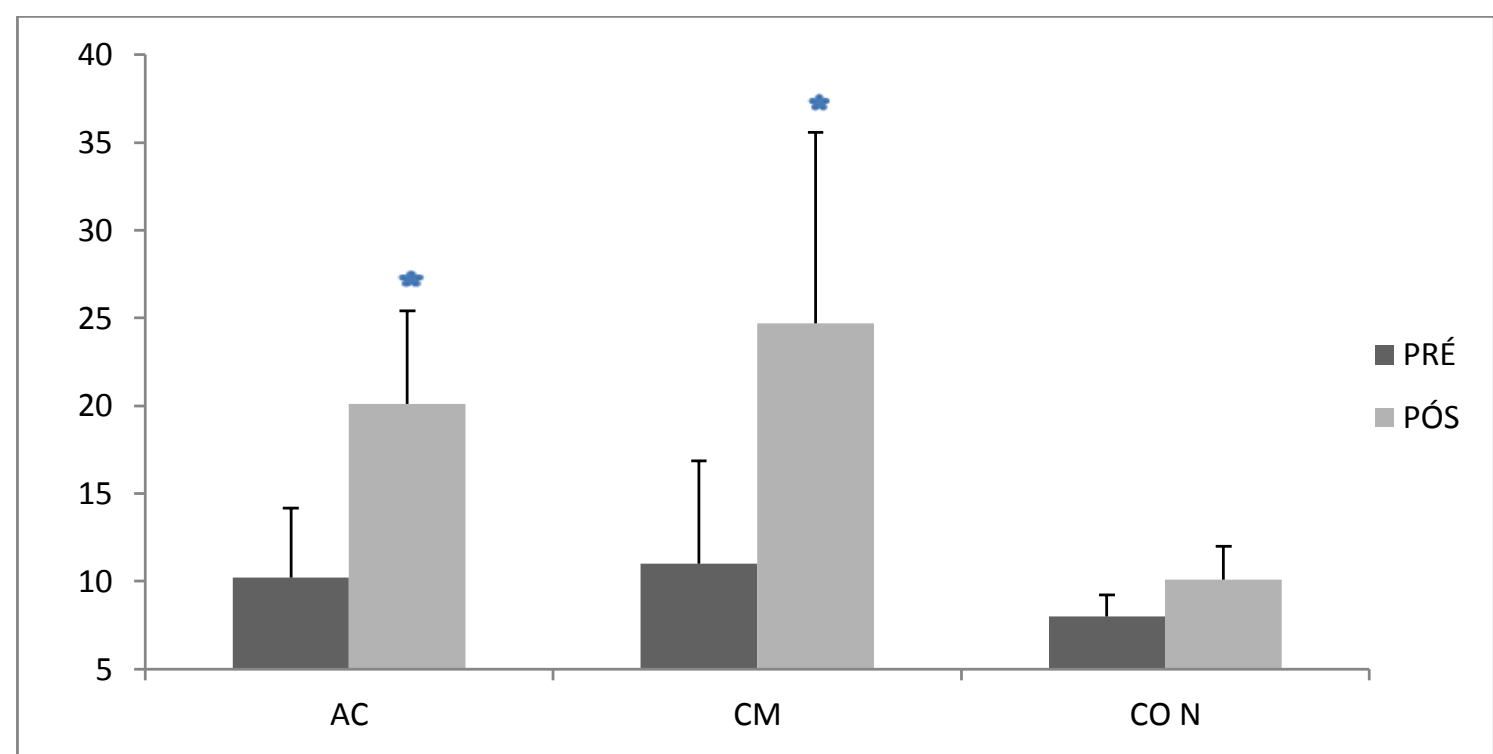

Figura 9 - Número de repetições com $70 \%$ do primeiro $1 \mathrm{RM}$ pré e pós treinamento no agachamento para os grupos $\mathrm{AC}, \mathrm{CM}$ e CON.

* diferença estatisticamente significativa pré e pós com $p \leq 0,05$ 


\section{DISCUSSÃO}

O objetivo do presente estudo foi comparar os efeitos de dois diferentes protocolos de TR nos ganhos de força e resistência de força em adolescentes. Para todas as variáveis testadas, os grupos $\mathrm{AC}$ e CM aumentaram significativamente a carga máxima de $1 \mathrm{RM}$ e o número máximo de repetições com $70 \%$ de $1 \mathrm{RM}$, mas não houve mudanças no grupo controle. Os aumentos foram maiores para os grupos experimentais em relação ao controle, mas não houve diferença entre os grupos AC e CM.

No supino, os valores de $1 \mathrm{RM}$ aumentaram em $14,79 \%$ para o grupo AC e $14,17 \%$ para o grupo CM, enquanto o grupo CON aumentou em 4,84\%. No agachamento, os aumentos no $1 \mathrm{RM}$ foram de $26,35 \%, 25,67 \%$ e $5,72 \%$ para os grupos $\mathrm{AC}, \mathrm{CM}$ e $\mathrm{CON}$, respectivamente. Os dois protocolos geraram ganhos significativos para aumento de força máxima, porém não houve diferença entre os treinos com maiores cargas e menos repetições ou cargas moderadas e altas repetições.

Existem diversos estudos que avaliam os efeitos do TR para ganho de força $\mathrm{e}$ resistência musculares em adultos, mas apenas dois estudos foram encontrados comparando diferentes protocolos em crianças. Até onde é do nosso conhecimento, presente estudo foi o primeiro a comparar, em adolescente, dois protocolos de treinos: altas cargas e baixas repetições ou cargas moderadas e altas repetições. Os resultados nesse trabalho acompanham parte da bibliografia em crianças e adultos.

Para os adultos, desde os primeiros estudos sobre TR, as pesquisas apoiaram a ideia de especificidade da tarefa relacionada a combinações de séries/repetições específicas, confirmando a teoria de um continuum de resistência de força de DeLorme $^{21}$ e Berger ${ }^{56}$ e indicaram, a partir daí, a relação de que cargas mais elevadas geram melhores resultados para força máxima. É possível encontrar diversos artigos e algumas revisões que reforçam a teoria de que protocolos com mais carga e menos repetições (ex. 2 a 6 RMs) são mais eficazes para aumentar a força máxima ${ }^{17-23,56}$.

Entretanto, outros autores refutam essa afirmação através de seus experimentos ou por revisões bibliográficas. Essas publicações sugerem não haver diferença entre o protocolo com altas cargas e menos repetições e os que utilizam mais repetições (ex. 12 ou 15 ou 20 RMs) com cargas moderadas. Em nosso estudo, 
os resultados apontam que os dois protocolos de treinamento AC (4 a 6 RMs) ou CM (12 a 15 RMs) são eficientes para aumentar a força máxima e a resistência de força, em adolescentes destreinados, o que está de acordo com alguns estudos em adultos $^{24-30}$ e crianças ${ }^{14}$.

Embora não tenha sido um estudo de treinamento, o estudo de ativação de unidades motoras realizado por Behm e colegas $^{69}$ pode ajudar a explicar os presentes resultados. O estudo envolveu 14 jovens do sexo masculino que estavam realizando TR, no mínimo, três vezes por semana durante pelo menos um ano. Foi analisada a ativação de unidades motoras dos participantes durante a contração voluntária e a eletricamente estimulada antes e após a realização de 5RM, 10RM e 20RM de rosca bíceps. De acordo com os resultados, não houve diferença significativa na ativação voluntária de unidades motoras para os três protocolos. Aparentemente, as três diferentes cargas utilizadas provocaram níveis de ativação similares de unidades motoras (93,5 a 95,5\%), porque houve esforço máximo em cada protocolo, sugerindo que é o grau de esforço que determina a ativação da unidade motora e não a quantidade de resistência ou tempo sob tensão.

Para analisar o que há de publicações na literatura a respeito do tema, alguns autores fizeram revisões bibliográficas e demonstram não haver base para afirmar que há diferença em usar maiores ou menores cargas para menos ou mais repetições. Carpinelli28 publicou uma extensa revisão, analisando os estudos que tratam da intensidade de treino e seus resultados para ganhos de força máxima e questionou os argumentos utilizados pelos pesquisadores para justificar que cargas mais altas e menores repetições são mais eficazes e afirma que os autores defendem essa teoria sem embasamento e cita apenas um artigo que comprove tal diferença. O autor expôs uma série de artigos que demonstram não haver diferença entre protocolos com mais ou menos repetições para aumento da força. Segundo ele, os estudos que apoiam a ideia de que mais seja melhor estão errados porque acreditam numa inferência inválida do princípio do tamanho do recrutamento das fibras musculares. Essa crença é de que, já que uma maior atividade da unidade motora gera uma maior produção de força, uma força maior (maior resistência) é necessária para a máxima ativação das unidades motoras. Para o autor, o importante é realizar repetições máximas independente de quantas sejam, ou seja, realizar 2 RMs ou 6 RMs ou 12 RMs ou 20 RMs fará com que, ao alcançar a fadiga momentânea, o estímulo seja suficiente para estimular maiores ativações das unidades motoras. 
Pouco depois, Jungblut ${ }^{30}$ publicou outra revisão mostrando o erro na interpretação do princípio de recrutamento de fibras e aponta que os estudos sobre ativações de unidades motoras e os experimentos com TR não apoiam a teoria de que cargas mais altas geram mais resultados para aumentos de força máxima, mas que, na verdade, os estudos suportam a premissa de que uma quantidade moderada de resistência vai produzir ganhos de força similares aos com altas cargas. E indica, ainda, que a participação popular em programas de treinamento de força seria maior caso as pessoas entendessem que treinar com cargas moderadas ao invés de cargas altas geram os mesmos benefícios e são especialmente aplicáveis para populações especiais, como os idosos ou pessoas com limitações neuromusculares ou ortopédicas e para pessoas saudáveis que desejam fazer musculação para uma vida com os benefícios que o TR promove.

Fisher e colaboradores ${ }^{29}$ escreveram um artigo de revisão e a pesquisa sugere que não é a carga elevada que determina o recrutamento de fibras, mas sim, a fadiga das unidades motoras de limiar inferior, resultando, assim, em um processo de recrutamento sequencial de unidades motoras de maior limiar durante a execução de repetições contínuas. Os autores concluem que não há evidencias científicas suficientes para provar que há diferenças significativas para ganho de força utilizando-se diferentes protocolos de repetições e intensidades. $E$ mais, sugerem que as intensidades de treino devem ser $>80 \%$ de $1 \mathrm{RM}$ e que as repetições sejam executadas até a falha, indicando ser esse o modelo ideal para maximizar a força máxima.

Podemos inferir, a partir dos resultados encontrados no presente estudo, que os resultados semelhantes para ganhos de força nos dois protocolos acompanham a bibliografia que relata a importância em realizar RMs e de alcançar a falha concêntrica nas séries executadas, independente se forem baixas repetições (4 a 6 ) ou altas repetições (12 a 15).

Dessa forma, o fato dos adolescentes estarem em idade intermediária entre a infância e a fase adulta e demonstrarem respostas específicas frente ao TR ${ }^{31,32,63,64}$ não parece tornar sua resposta diferente da encontrada em crianças ou adultos. Os dados mostram que os adolescentes obtiveram resultados semelhantes aos encontrados em parte da literatura em adultos e na literatura mais recente em crianças para ganho de força máxima usando protocolos com diferentes números de RMs. 
Quanto aos resultados de resistência de força do nosso estudo, os grupos experimentais tiveram aumentos significativos em relação ao grupo controle, mas também não houve diferença entre o grupo AC e CM. Os testes realizados com $70 \%$ da carga máxima, revelaram que, para supino, o grupo AC aumentou em 14,51\% e o grupo CM em $21,71 \%$, o grupo CON diminui em - 4,72\% o número de repetições executadas. No agachamento, o aumento foi de $31,43 \%$ e $32,39 \%$, para grupo AC e $\mathrm{CM}$, respectivamente, e $11,34 \%$ de aumento para o grupo CON.

Em crianças, os dois estudos de Faigenbaum ${ }^{5,14}$ apontam que maiores repetições são mais eficazes para aumentar a resistência muscular. No primeiro estudo, os ganhos resultantes no grupo $\mathrm{CM}(13,1 \pm 6,2$ repetições) foram significativamente maiores do que os resultantes do treinamento do grupo AC $(8,7 \pm$ 2,9 repetições). No supino, apenas o grupo de altas repetições demonstrou ganhos em resistência muscular (5,2 $\pm 3,6$ repetições) que foram significativamente maiores do que os ganhos nos indivíduos do grupo controle. No segundo trabalho, apenas o grupo CM aumentou significativamente seus valores nos testes de resistência de força. O autor aponta que os ganhos induzidos pelo treinamento de força durante a infância tem sido atribuídos, principalmente, às adaptações neuromusculares ao invés de fatores hipertróficos.

$\mathrm{O} \mathrm{ACSM}^{70}$ afirma que quando o treinamento é para a resistência muscular em adultos, as pessoas devem usar cargas leves ou moderadas (40-60\% 1RM) e realizar repetições elevadas (> 15) com curtos períodos de descanso (<90s). Os resultados de Campos et al. ${ }^{20 a}$ poiam essa teoria. A resistência de força foi medida pelo número máximo de repetições a $60 \% 1 \mathrm{RM}$ e, no leg press, o grupo de altas repetições $(2 \mathrm{x}$ 20 a 28 RMs) melhorou em 94\%, o grupo de repetições intermediárias ( 3 x 9 a 11 RMS) melhorou em $10 \%$, e piorou em $20 \%$ para o grupo de baixas repetições ( $4 \times 3$ a $5 \mathrm{RMs}$ ) e diminuiu $19 \%$ para controle.

No entanto, outros estudos apontam resultados opostos aos acima relatados. Anderson e Kearney ${ }^{22}$ examinaram os efeitos de três diferentes protocolos de treinamento sobre a resistência muscular (medida pelo número de repetições possíveis no supino). Os participantes foram divididos em grupos de baixas repetições (3 x 6-8 RMs), repetições médias ( 2 x 30-40 RMs) e altas repetições ( 1 x 100-150 RMs). Não foram encontradas significativas diferenças entre os grupos para melhorias na resistência muscular. Stone e Coulter ${ }^{24}$ examinaram os efeitos de 3 protocolos de TR ( 3 × 6-8 RMs, 2 × 15-20 RMs e 1 × 30-40 RMs) sobre a resistência 
muscular de mulheres destreinadas. Mais uma vez, não foram encontradas diferenças significativas entre os grupos na resistência muscular após o treinamento.

Assim, temos resultados conflitantes, também, sobre os efeitos do TR na resistência de força em adultos. Os resultados do nosso estudo acompanham Anderson e Kearney ${ }^{22}$, Stone e Coulter ${ }^{24}$ e Fisher et al. ${ }^{29}$ e reforçam a teoria de que não há diferenças significativas entre os protocolos com altas cargas e menor número de repetições máximas $(A C)$ ou cargas moderadas e maiores números de repetições máximas (CM) para ganhos na resistência de força em adolescentes de ambos os sexos destreinados. Fisher et al..$^{29} \mathrm{em}$ seu artigo de revisão sugerem as cargas de treinamento devem estar acima de $80 \%$ de $1 \mathrm{RM}$ e que as repetições devem ser realizadas até a falha momentânea sendo esse o método ideal para maximizar os ganhos na resistência muscular.

Os resultados encontrados no presente estudo mostram que para força máxima, os adolescentes apresentaram respostas semelhantes a das encontradas em parte dos estudos em crianças ${ }^{14}$ e adultos ${ }^{25-31}$. E, para resistência de força, acompanham os resultados de parte dos estudos em adultos ${ }^{23,25,30}$

Os resultados positivos tanto do grupo AC quanto do grupo $\mathrm{CM}$ possivelmente estão relacionados ao fato de ambos terem treinado até a falha concêntrica, executando sempre repetições máximas em cada série. Reforçando, assim, o conceito de que a fadiga momentânea gera estímulo suficiente para ativar outras unidades motoras, não sendo a carga elevada que determina o recrutamento de fibras, mas sim a fadiga das unidades motoras de limiar inferior, que resulta em um processo de recrutamento sequencial. 


\section{CONCLUSÃO}

Os resultados do presente estudo apontam que para aumentar a força máxima e a resistência de força em adolescentes, pode-se utilizar protocolos com altas cargas e baixas repetições (AC) ou com cargas moderadas e altas repetições (CM). Os dados mostram não haver diferença entre os protocolos AC e CM para nenhuma das variáveis analisadas e ambos se mostraram eficientes para aumentar tanto a força máxima quanto a resistência de força.

Os efeitos do TR em adolescentes precisam ser melhor estudados e futuras pesquisas devem ser conduzidas no intuito de verificar outros modelos de treinamento e os fatores fisiológicos presente nas respostas específicas da puberdade, bem como comparar os efeitos de treinos submáximos com treinos máximos.

Fica assim, a cargo dos educadores físicos e profissionais ligados a atividade física, escolher dada a individualidade biológica e a fase de treino, a melhor estratégia de treino a ser usada, sabendo que ambas trarão significativos benefícios. 


\section{BIBLIOGRAFIA}

1. Fleck SJ, Kraemer WJ. Fundamentos do Treinamento de Força Muscular. 3 edição ed2006.

2. Mascarenhas LPG, Neto AS, Vasconcelos IA, et al. Efeitos de duas intensidades de treinamento aeróbio na composição corporal e na potencia aeróbia e anaeróbia de meninos pré púberes. Revista Brasileira de Educação Física Esporte, Lazer e Desporto. 2008;22:81-89.

3. Tourinho Filho $\mathrm{H}$, Tourinho LSPR. Crianças, adolescentes e atividade física: Aspectos maturacionais e funcionais. Revista Paulista Educação Física. 1998;3:71-84.

4. Faigenbaum AD, Kraemer WJ, Cahill B, et al. Youth Resistance Training: Position Statement Paper and Literature Review: Position Statement. Strength \& Conditioning Journal. 1996;18(6):62-76.

5. Faigenbaum $A D$, Westcott $W L$, Loud RL, Long $C$. The effects of different resistance training protocols on muscular strength and endurance development in children. Pediatrics. Jul 1999;104(1):e5.

6. Hamill BP. Relative safety of weightlifting and weight training. The Journal of Strength \& Conditioning Research. 1994;8(1):53-57.

7. Barbieri $D$, Zaccagni $L$. Strength training for children and adolescents: Benefits and risks. Collegium antropologicum. 2013;37(2):219-225.

8. Fleck SJ. Perceived benefits and concerns of resistance training for children and adolescents. Revista Kronos. 2011;10(1):15 - 20.

9. Faigenbaum $A D$, Myer GD. Resistance training among young athletes: safety, efficacy and injury prevention effects. British Journal of Sports Medicine. Jan 2010;44(1):56-63.

10. Faigenbaum $A D$, Kraemer $W J$, Blimkie $C J$, et al. Youth resistance training: updated position statement paper from the national strength and conditioning association. The Journal of Strength \& Conditioning Research. Aug 2009;23(5 Suppl):S60-79.

11. Guy JA, Micheli LJ. Strength training for children and adolescents. J Am Acad Orthop Surg. Jan-Feb 2001;9(1):29-36.

12. Benetti $G$, Schneider P, Meyer F. Os Benefícios do Esporte e a Importância da Treinabilidade da Força Muscular de Pré-Puberes Atletas de Voleibol. 
Revista Brasileira de Cineantropometria e Desempenho Humano. 2005;7:8793.

13. Weineck J. Treinamento Ideal. 9 ediçao ed1999.

14. Faigenbaum AD, Milliken L, Moulton L, Westcott WL. Early muscular fitness adaptations in children in response to two different resistance training regimens. Pediatric Exercise Science. 2005;17(3):237.

15. Ortega FB, Silventoinen $\mathrm{K}$, Tynelius $\mathrm{P}$, Rasmussen $\mathrm{F}$. Muscular strength in male adolescents and premature death: cohort study of one million participants. British Medical Journal. 2012;345.

16. Berger R. Effect of varied weight training programs on strength. Research Quarterly. American Association for Health, Physical Education and Recreation. 1962;33(2):168-181.

17. Burd NA, Mitchell CJ, Churchward-Venne TA, Phillips SM. Bigger weights may not beget bigger muscles: evidence from acute muscle protein synthetic responses after resistance exercise. Applied Physiology, Nutrition, and Metabolism. 2012;37(3):551-554.

18. Mitchell CJ, Churchward-Venne TA, West DWD, et al. Resistance exercise load does not determine training-mediated hypertrophic gains in young men. Journal of Applied Physiology. 2012;113:71-77.

19. Schoenfeld BJ, Ratamess NA, Peterson MD, Contreras B, Sonmez G, Alvar BA. Effects of different volume-equated resistance training loading strategies on muscular adaptations in well-trained men. The Journal of Strength \& Conditioning Research. 2014;28(10):2909-2918.

20. Campos GE, Luecke TJ, Wendeln HK, et al. Muscular adaptations in response to three different resistance-training regimens: specificity of repetition maximum training zones. European journal of applied physiology. 2002;88(12):50-60.

21. DeLorme TL. Restoration of muscle power by heavy-resistance exercises. Journal of Bone and Joint Surgery. 1945;27(4):645-667.

22. Anderson T, Kearney JT. Effects of three resistance training programs on muscular strength and absolute and relative endurance. Research Quarterly for Exercise and Sport. 1982;53(1):1-7. 
23. Tan B. Manipulating Resistance Training Program Variables to Optimize Maximum Strength in Men: A Review. The Journal of Strength \& Conditioning Research. 1999;13(3):289-304.

24. Stone WJ, Coulter SP. Strength/Endurance Effects From Three Resistance Training Protocols With Women. The Journal of Strength \& Conditioning Research. 1994;8(4):231-234.

25. O'Shea P. Effects of selected weight training programs on the development of strength and muscle hypertrophy. Research Quarterly. American Association for Health, Physical Education and Recreation. 1966;37(1):95-102.

26. Chestnut JL, Docherty D. The effects of 4 and 10 repetition maximum weighttraining protocols on neuromuscular adaptations in untrained men. The Journal of Strength \& Conditioning Research. 1999;13(4):353-359.

27. Withers RT. Effect of varied weight-training loads on the strength of university freshmen. Research Quarterly. American Association for Health, Physical Education and Recreation. 1970;41(1):110-114.

28. Carpinelli RN. The size principle and a critical analysis of the unsubstantiated heavier-is-better recommendation for resistance training. Journal of Exercise Science \& Fitness. 2008;6(2):67-86.

29. Fisher J, Steele J, Bruce-Low S, Smith D. Evidence-based resistance training recommendations. Med Sport. 2011;15(3):147-162.

30. Jungblut $\mathrm{S}$. The correct interpretation of the size principle and its practical application to resistance training. Medicina Sportiva. 2009(13):203-209.

31. Chen TC, Chen H-L, Liu Y-C, Nosaka K. Eccentric exercise-induced muscle damage of pre-adolescent and adolescent boys in comparison to young men. European journal of applied physiology. 2014;114(6):1183-1195.

32. Faigenbaum AD, Ratamess NA, McFarland J, et al. Effect of rest interval length on bench press performance in boys, teens, and men. Pediatric Exercise Science. 2008;20(4):457-469.

33. Condessa I, Santos E. O lugar da atividade física escolar na educação da criança: Perceção de pais e de educadores/professores. E-Balonmano. com: Revista de Ciencias del Deporte. 2015;11(4):9-10.

34. Berger RA. Comparison of the effect of various weight training loads on strength. Research Quarterly. American Association for Health, Physical Education and Recreation. 1965;36(2):141-146. 
35. Capen EK. The effect of systemic weight training on power, strength and endurance. Research. Quarterly. 1950;21:83-89.

36. MacQueen IJ. Recent advances in the technique of progressive resistance exercise. The British Medical Journal. 1954:1193-1198.

37. Pollock ML, Franklin BA, Balady GJ, et al. Resistance exercise in individuals with and without cardiovascular disease benefits, rationale, safety, and prescription an advisory from the committee on exercise, rehabilitation, and prevention, council on clinical cardiology, American Heart Association. Circulation. American Heart Association. 2000;101(7):828-833.

38. Pollock ML, Gaesser GA, Butcher JD, et al. ACSM position stand: the recommended quantity and quality of exercise for developing and maintaining cardiorespiratory and muscular fitness, and flexibility in healthy adults. Med Sci Sports Exerc. 1998;30(6):975-991.

39. Silva MS. Efeitos Agudos de Diferentes Intensidades e Intervalos de Recuperação do Treinamento Resistido em Atletas Jovens. Brasília: Faculdade de Educação Física, Universidade Católica de Brasília; 2009.

40. Medicine ACoS. American College of Sports Medicine position stand. Progression models in resistance training for healthy adults. Medicine and science in sports and exercise. 2009;41(3):687.

41. Gordon NF, Gulanick M, Costa F, et al. Physical activity and exercise recommendations for stroke survivors an American heart association scientific statement from the council on clinical cardiology, subcommittee on exercise, cardiac rehabilitation, and prevention; the council on cardiovascular nursing; the council on nutrition, physical activity, and metabolism; and the stroke council. Stroke. 2004;35(5):1230-1240.

42. Stone MH, Fleck SJ, Triplett NT, Kraemer WJ. Health-and performance-related potential of resistance training. Sports Medicine. 1991;11(4):210-231.

43. Fleck SJ, Kraemer W. Designing Resistance Training Programs, 4E: Human Kinetics; 2014.

44. Lloyd RS, Faigenbaum AD, Stone $\mathrm{MH}$, et al. Position statement on youth resistance training: the 2014 International Consensus. British journal of sports medicine. 2013:bjsports-2013-092952.

45. Faigenbaum AD. Strength training for children and adolescents. Clinical Journal of Sport Medicine. Oct 2000;19(4):593-619. 
46. Hejna WF, Rosenberg A, Buturusis DJ, Krieger A. The prevention of sports injuries in high school students through strength training. Strength \& Conditioning Journal. 1982;4(1):28-31.

47. Lloyd R, Faigenbaum A, Myer G, et al. UKSCA position statement: Youth resistance training. United Kingdom Strength and Conditioning Association. 2012;26:26-39.

48. Dias IBF. Efeito dos exercícios resistidos sobre a função endotelial, parâmetros hemodinâmicos e metabólicos, modulação autonômica, biomarcadores inflamatórios, composição corporal e condicionamento físico de adolescentes obesos. Rio de Janeiro: Centro Biomédico, Universidade do Estado do Rio de Janeiro; 2013.

49. Foschini D, Araújo RC, Bacurau RF, et al. Treatment of obese adolescents: the influence of periodization models and ACE genotype. Obesity. 2010;18(4):766-772.

50. Myer GD, Faigenbaum AD, Ford KR, Best TM, Bergeron MF, Hewett TE. When to initiate integrative neuromuscular training to reduce sports-related injuries in youth? Current sports medicine reports. 2011;10(3):155.

51. Ruiz JR, Castro-Piñero J, Artero EG, et al. Predictive validity of health-related fitness in youth: a systematic review. British journal of sports medicine. 2009.

52. Granacher U, Muehlbauer T, Doerflinger B, Strohmeier R, Gollhofer A. Promoting strength and balance in adolescents during physical education: effects of a short-term resistance training. The Journal of Strength \& Conditioning Research. 2011;25(4):940-949.

53. Faigenbaum AD, Westcott WL, Micheli LJ, et al. The effects of strength training and detraining on children. The Journal of Strength \& Conditioning Research. 1996;10(2):109-114.

54. Eiholzer U, Meinhardt U, Petrò R, Witassek F, Gutzwiller F, Gasser T. Highintensity training increases spontaneous physical activity in children: a randomized controlled study. The Journal of pediatrics. 2010;156(2):242-246.

55. Kraemer WJ, Hakkinem K. Treinamento de Força para o Esporte. 1 ed2004.

56. Berger RA. Optimum repetitions for the development of strength. Research Quarterly. American Association for Health, Physical Education and Recreation. 1962;33(3):334-338. 
57. Holm L, Reitelseder S, Pedersen TG, et al. Changes in muscle size and MHC composition in response to resistance exercise with heavy and light loading intensity. Journal of Applied Physiology. 2008;105(5):1454-1461.

58. Rhea MR, Alvar BA, Burkett LN, Ball SD. A meta-analysis to determine the dose response for strength development. Medicine and science in sports and exercise. 2003;35(3):456-464.

59. Faigenbaum AD, Zaichkowsky LD, Westcott WL, Micheli LJ, Fehlandt AF. The effects of a twice-a-week strength training program on children. Pediatric Exercise Science. 1993;5:339-339.

60. Davim RMB, Germano RM, Menezes RMV, Carlos DJD. Adolescente/adolescência: revisão teórica sobre uma fase crítica da vida. Revista da Rede de Enfermagem do Nordeste-Rev Rene. 2012;10(2).

61. Ferreira THS, Farias MA, Silvares EFM. Adolescência Através dos Séculos. Psicologia: Teoria e Pesquisa. 2010;26(2):227-234.

62. Machado DRL, Barbanti VJ. Maturação esquelética e crescimento em crianças e adolescentes. Revista Brasileira de Cineantropometria e Desempenho Humano. 2007;9(1):12-20.

63. Bottaro M, Brown LE, Celes R, Martorelli S, Carregaro R, de Brito Vidal JC. Effect of rest interval on neuromuscular and metabolic responses between children and adolescents. Pediatric Exercise Science. 2011;23(3):311.

64. Tibana RA, Prestes J, da Cunha Nascimento D, Martins OV, De Santana FS, Balsamo S. Higher muscle performance in adolescents compared with adults after a resistance training session with different rest intervals. The Journal of Strength \& Conditioning Research. 2012;26(4):1027-1032.

65. Thomas JR, Nelson JK, Silverman SJ. Métodos de pesquisa em atividade física: Artmed; 2012.

66. Gentil P, Bottaro M. Effects of training attendance on muscle strength of young men after 11 weeks of resistance training. Asian journal of sports medicine. 2013;4(2):101.

67. Martorelli S. Mangas compress $i$ vas : ef e it os no desempenho neuromuscu I ar e metabó I i co. Brasília: Faculdade de Educaçao Física, Universidade de Brasília; 2012. 
68. Hatfield DL, Kraemer WJ, Spiering BA, et al. The impact of velocity of movement on performance factors in resistance exercise. The Journal of Strength \& Conditioning Research. 2006;20(4):760-766.

69. Behm D, Sale D. Velocity specificity of resistance training. Sports Medicine. 1993;15(6):374-388.

70. Ratamess N, Alvar B, Evetoch T, Housh T, Kibler W, Kraemer W. Progression models in resistance training for healthy adults [ACSM position stand]. Med Sci Sports Exerc. 2009;41(3):687-708. 


\section{ANEXO I}

\section{ANAMNESE}

Nome:

Data Nasc: Idade Telefones:

Email:

Nome do Responsável legal: Tels do Responsável Legal:

\section{Atividade Física}

1.1 Pratica treinamento físico regular? a anos e meses.

Qual(is)?

Com que frequência semanal? vezes por semana. Quantas horas por dia de treino? horas

\section{Hábitos e Histórico pessoal: ( S ) para sim, ( N ) para não}

2.1 Apresenta e/ou apresentou problemas:

( ) Cardiológicos qual(is)?

( ) Pressão arterial: ( ) Hipertensão ( ) Hipotensão( ) Circulatórios

( ) Diabetes tipo___ ( ) Colesterol elevado ( ) Acidente vascular cerebral/derrame

( ) Stress( ) Respiratórios( ) Endócrino/ Hormonal( ) Ortopédicos

()Outros:

2.2 Existe ou existiu em sua família alguma incidência dos problemas relacionados acima? ( ) Sim ( ) Não Qual(is) e com quem?

2.3 Faz uso regular e/ou está tomando algum medicamento (s)? ( ) Sim ( ) Não Qual(is)

2.4 Faz acompanhamento nutricional? ( ) Não ( ) Nutricionista ( ) Endocrinologista

2.5 Quantas refeições faz diariamente? refeições. Obs.

2.6 Atualmente toma qualquer tipo de suplementos alimentares ou vitaminas?

( ) Sim ( ) Não Qual(is)?

2.7 Já sofreu alguma lesão óssea ou articular? ( ) Sim ( ) Não

Qual (is)?

2.8 Já se submeteu a cirurgia(s)? ( ) Sim ( ) Não

Qual (is) e há quanto tempo?

2.8 Sente dores de cabeça fortes e frequentes? ( ) Sim ( ) Não 
2.9 Sente dores no peito quando faz ou não atividade física? ( ) Sim ( ) Não

2.10 Você costuma ter vertigem ou já perdeu a consciência? ( ) Sim ( ) Não Frequência?

\section{Tabagismo}

3.1 Tem (ou teve) hábito de fumar? ( ) Sim ( ) Não Fumo_ cigarros por dia a anos. Fumei há anos

\section{Conclusão}

4.1 Possuo restrições médicas em relação a pratica de exercícios físicos?( ) Sim ( ) Não Qual(is)

4.2 Gostaria de fazer alguma observação ou comentário sobre suasaúde?

Assinatura do Responsável Legal

Data: / / 


\section{ANEXO II \\ TERMO DE CONSENTIMENTO LIVRE E ESCLARECIDO}

Seu filho está convidado a participar de um estudo intitulado Efeitos de Diferentes Protocolos de Treinamento Resistido no Desempenho Neuromuscular em Adolescentes.

O treinamento resistido, ou musculação, descreve um tipo de exercício que exige que a musculatura do corpo promova movimentos contra a oposição de uma força geralmente exercida por algum tipo de equipamento, tais como pesos livres e aparelhos de musculação, com diferentes velocidades de movimento e uma variedade de possibilidades metodológicas.

O propósito da pesquisa é verificar se o treinamento resistido, duas vezes por semana e com duração média de 40 minutos, aumentará a força, a resistência de força, a potência e capacidades físicas da amostra, bem como verificar qual o protocolo de treino será mais eficiente para alcançar esses objetivos.

Evidências científicas recentes têm indicado que se pode obter diversos benefícios com o treinamento resistido em adolescentes, como: força e resistência muscular, melhora do desempenho esportivo, prevenção de lesões no esporte e em atividades recreativas, reabilitação de lesões, melhora da composição corporal, aumento da densidade mineral óssea, aumento da capacidade cardiorrespiratória, diminuição de lipídios sanguíneos, melhoria do bem estar psicossocial, dentre outros, sem ocasionar lesões.

Como voluntário seu filho será submetido a uma entrevista e uma avaliação, na qual será verificada a condição de saúde em geral. Após essa avaliação, caso seja considerado apto a participar, será instruído verbalmente sobre todos os procedimentos do estudo e convidado a participar.

A participação do seu filho envolverá avaliação antropométrica (peso e altura); testes de determinação da carga de treinamento para os exercícios (teste de 1RM), teste de resistência de força, teste de potência, teste de salto vertical e teste de corrida rápida. 
Os procedimentos que serão utilizados nos testes físicos não apresentam fatores de risco além daqueles comuns a aula de Educação Física ou de musculação, pois são realizados com movimentos do cotidiano de praticantes de atividades físicas, não inferindo risco à sua realização.

A duração do estudo será de aproximadamente 3 meses, sendo 2 semanas para testes, uma no início e outra ao final, e 10 semanas de treinamentos.

O estudo não envolve gastos aos participantes. Todos os materiais e equipamentos necessários para os testes serão providenciados pelos pesquisadores, e eventuais despesas, como transporte até o CIEF, serão custeados pelo pesquisador.

A participação do seu filho é de extrema importância para a Ciência e o mesmo pode se beneficiar das novas estratégias de treinamento, melhorando seu rendimento e performance esportivos. De uma forma ampla, os dados obtidos no estudo podem trazer benefícios aos praticantes de treinamento resistido, por possibilitar a prescrição de treinos mais eficientes que possam otimizar a obtenção dos resultados desejados.

É importante destacar que seu filho poderá abandonar o estudo a qualquer momento que desejar, sem qualquer constrangimento ou implicação, bastando para isso informar ao avaliador sobre sua decisão e que seu filho poderá vir a fazer jus a indenização diante de eventuais danos físicos decorrentes da pesquisa.

Os participantes da pesquisa, bem como seus responsáveis legais, terão acesso, em qualquer tempo, às informações sobre procedimentos, riscos e benefícios relacionados ao estudo e aos resultados parciais e finais.

Todas as informações obtidas neste trabalho serão confidenciais e, em nenhum momento, o nome do avaliado será divulgado, assim como os pesquisadores comprometem-se a utilizar os dados genéricos deste trabalho para publicações e divulgações em artigos científicos e eventos da área.

Essa pesquisa foi aprovada quanto a sua ética cientifica pelo Comitê de Ética em Pesquisa Envolvendo Seres Humanos, da Faculdade de Ciências da Saúde da 
Universidade de Brasília, de acordo com as normas da Resolução 466/2012 do Conselho Nacional de Saúde do Ministério da Saúde. A este Comitê cabe a solução ou o encaminhamento de quaisquer questões éticas que possam surgir nessa pesquisa, de interesse do Voluntario ou dos Pesquisadores.

Em caso de dúvida ou reclamação, o senhor poderá entrar em contato com os pesquisadores responsáveis (Ari Rodrigo Assunção 92129212 ou Dr. Paulo Gentil 81188118) ou com o Comitê de Ética e Pesquisa da Faculdade de Ciência da Saúde da UnB (CEP/FS) pelo telefone 31071947.

Declaro que, após convenientemente esclarecido pelo pesquisador e ter entendido o que me foi explicado, consinto que meu filho participe do presente projeto de pesquisa e assino em duas vias iguais, com duas folhas cada, uma para o responsável legal e outra para o pesquisador.

Nome do aluno participante do estudo:

Assinatura do aluno

Nome do responsável legal:

RG do responsável legal:

Assinatura do responsável

Assinatura do pesquisador

Telefones para contato:

Brasília,

Prof. Ari Rodrigo Assunção: 9212-9212 (pesquisador responsável)

Prof. Dr. Paulo Gentil: 8118-8118 (orientador da pesquisa) 


\section{ANEXO III}

\section{TERMO DE ASSENTIMENTO LIVRE E ESCLARECIDO}

Você está convidado a participar de um estudo intitulado Efeitos de Diferentes Protocolos de Treinamento Resistido no Desempenho Neuromuscular em Adolescentes.

O treinamento resistido, ou musculação, descreve um tipo de exercício que exige que a musculatura do corpo promova movimentos contra a oposição de uma força geralmente exercida por algum tipo de equipamento, tais como pesos livres e aparelhos de musculação, com diferentes velocidades de movimento e uma variedade de possibilidades metodológicas.

O propósito da pesquisa é verificar se o treinamento resistido, duas vezes por semana e com duração média de 40 minutos, aumentará a sua força, a resistência de força, a potência e capacidades físicas, bem como verificar qual o protocolo de treino será mais eficiente para alcançar esses objetivos.

Evidências científicas recentes têm indicado que se pode obter diversos benefícios com o treinamento resistido em adolescentes, como: força e resistência muscular, melhora do desempenho esportivo, prevenção de lesões no esporte e em atividades recreativas, reabilitação de lesões, melhora da composição corporal, aumento da densidade mineral óssea, aumento da capacidade cardiorrespiratória, diminuição de lipídios sanguíneos, melhoria do bem estar psicossocial, dentre outros, sem ocasionar lesões.

Como voluntário você será submetido a uma entrevista e uma avaliação, na qual será verificada a condição de saúde em geral. Após essa avaliação, caso seja considerado apto a participar, será instruído verbalmente sobre todos os procedimentos do estudo e convidado a participar.

A sua participação envolverá avaliação de peso e altura; testes de determinação da carga de treinamento para os exercícios (teste de 1RM), teste de resistência de força, teste de potência, teste de salto vertical e teste de corrida rápida. 
Os procedimentos que serão utilizados nos testes físicos não apresentam fatores de risco além daqueles comuns a aula de Educação Física ou de musculação, pois são realizados com movimentos do cotidiano de praticantes de atividades físicas, não inferindo risco à sua realização.

A duração do estudo será de aproximadamente 3 meses, sendo 2 semanas para testes, uma no início e outra ao final, e 10 semanas de treinamentos.

O estudo não envolve gastos aos participantes. Todos os materiais e equipamentos necessários para os testes serão providenciados pelos pesquisadores, além de eventuais despesas, como transporte até o CIEF, serão custeadas pelo pesquisador.

A sua participação é de extrema importância para a Ciência e você pode se beneficiar das novas estratégias de treinamento, melhorando seu rendimento e performance esportivos. De uma forma ampla, os dados obtidos no estudo podem trazer benefícios aos praticantes de treinamento resistido, por possibilitar a prescrição de treinos mais eficientes que possam otimizar a obtenção dos resultados desejados.

É importante destacar que você poderá abandonar o estudo a qualquer momento que desejar, sem qualquer constrangimento ou implicação, bastando para isso informar ao avaliador sobre sua decisão e fará jus a indenização diante de eventuais danos físicos decorrentes da pesquisa.

Você, bem como seus responsáveis legais, terá acesso, em qualquer tempo, às informações sobre procedimentos, riscos e benefícios relacionados ao estudo e aos resultados parciais e finais.

Todas as informações obtidas neste trabalho serão confidenciais e, em nenhum momento, seu nome será divulgado, assim como os pesquisadores comprometem-se a utilizar os dados genéricos deste trabalho para publicações e divulgações em artigos científicos e eventos da área.

Essa pesquisa foi aprovada quanto a sua ética cientifica pelo Comitê de Ética em Pesquisa Envolvendo Seres Humanos, da Faculdade de Ciências da Saúde da 
Universidade de Brasília, de acordo com as normas da Resolução 466/2012 do Conselho Nacional de Saúde do Ministério da Saúde. A este Comitê cabe a solução ou o encaminhamento de quaisquer questões éticas que possam surgir nessa pesquisa, de interesse do Voluntario ou dos Pesquisadores.

Em caso de dúvida ou reclamação, pode entrar em contato com os pesquisadores responsáveis (Ari Rodrigo Assunção - 9212-9212 ou Dr. Paulo Gentil -8118-8118) ou com o Comitê de Ética e Pesquisa da Faculdade de Ciência da Saúde da UnB (CEP/FS) pelo telefone 3107-1947.

Declaro que, após convenientemente esclarecido pelo pesquisador e ter entendido o que me foi explicado, consinto em participar do presente projeto de pesquisa e assino em duas vias iguais, com duas folhas cada, uma para o aluno e outra para o pesquisador.

Nome do aluno participante do estudo:

Assinatura do aluno

Assinatura do pesquisador

Telefones para contato:

Brasília,

Prof. Ari Rodrigo Assunção: 9212-9212 (pesquisador responsável)

Prof. Dr. Paulo Gentil: 8118-8118 (orientador da pesquisa) 


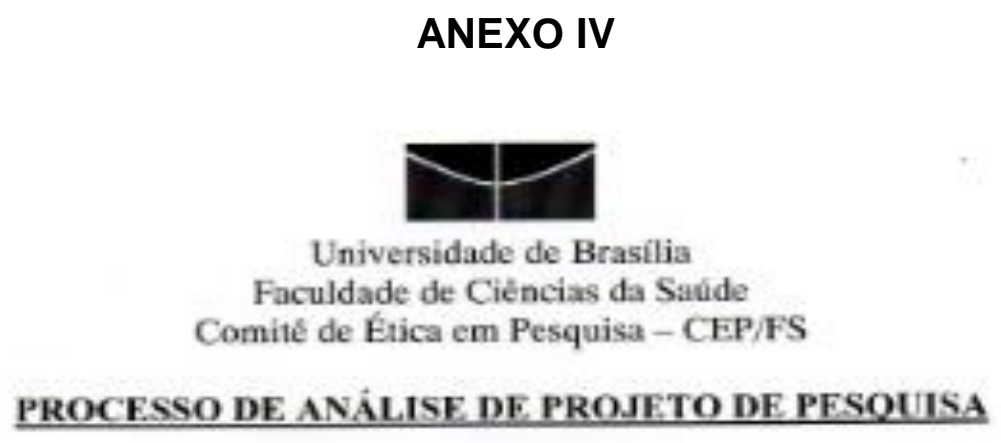

ritulo do Projeto: "EFETTOS DE DIFERENTES PROTOCOLOS DE IREINAMENTO RESISTIDO NA FUNCĀO NEUROMUSCULAR EM ADOLESCENTES

\section{Pesquisadora Responsáivel: ARI RODRIGO ASSUNÇẢO RODRIGUES}

Data de Entrada: 05/03/2015

CAAE: 38384514.6 .0000 .0030

Com base na Resoluçio 466/12, do CNS/MS, que regulamenta a ética em pesquisa com seres humanos, o Comitê de Ética em Pesquisa com Seres Hemanos da Faculdade de Ciéncias da Saúde da Universidade de Brasilia, após anślise dos aspectos éticos e do contexto técnico-cientifico, resolveu APROVAR o projeto intitulado "EFETTOS DE DIFERENTES PROTOCOLOS DE TRFINAMENTO RESISTIDO NA FUNCCÃO NEUROMUSCULAR EM ADOLESCENTES", Parecer $n^{\circ} 997.140$, em 18 de março de 2015.

Notifica-se o(a) pesquisador(a) responsável da obrigatoriedade da apresentaçăo de um relatório semestral e relatório final sobre o desenvolvimento do projeto, no prazo de 1 (um) ano a contar da data de aprovaçio.

Brasflia, 09 de junbo de 2015.

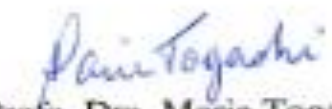

Profa. Dra. Maric Togashi

Coocdenadora do CEP-FS UnB 